\title{
Dynamically Induced Displacements of a Persistent Cold-Air Pool
}

\author{
Neil P. Lareau • John D. Horel
}

Received: 12 September 2013 / Accepted: 19 August 2014 / Published online: 12 September 2014

(C) The Author(s) 2014. This article is published with open access at Springerlink.com

\begin{abstract}
We examine the influence of a passing weather system on a persistent cold-air pool (CAP) during the Persistent Cold-Air Pool Study in the Salt Lake Valley, Utah, USA. The CAP experiences a sequence of along-valley displacements that temporarily and partially remove the cold air in response to increasing along-valley winds aloft. The displacements are due to the formation of a mountain wave over the upstream topography as well as adjustments to the regional horizontal pressure gradient and wind-stress divergence acting on the CAP. These processes appear to help establish a balance wherein the depth of the CAP increases to the north. When that balance is disrupted, the CAP tilt collapses, which sends a gravity current of cold air travelling upstream and thereby restores CAP conditions throughout the valley. Intra-valley mixing of momentum, heat, and pollution within the CAP by Kelvin-Helmholtz waves and seiching is also examined.
\end{abstract}

Keywords Cold-air pool - Inversion - Kelvin-Helmholtz instability · Mountain wave · Seiche $\cdot$ Stable boundary layer $\cdot$ Turbulent mixing

\section{Introduction}

The disruption of persistent cold-air pools (CAPs) arising from passing weather systems is examined. CAPs are decoupled air masses that form in mountain valleys and basins due to cooling of the air near the surface, warming of the air aloft, or both (Whiteman et al. 1999). The resulting stable stratification suppresses vertical mixing while the confining topography prevents advection and favours air stagnation (Zängl 2003). Persistent CAPs are simply CAPs surviving through more than one diurnal cycle (Whiteman et al. 2001).

Persistent CAPs are often accompanied by adverse societal impacts. When they occur in densely settled valleys, the emissions from vehicles, home heating, and industrial sources

N. P. Lareau $(\bowtie) \cdot$ J. D. Horel

Department of Atmospheric Sciences, University of Utah, 135 S 1460 E Room 819 WBB,

Salt Lake City, UT 84112-0110, USA

e-mail: neil.lareau@utah.edu 
accumulate, leading to poor air quality (Reddy et al. 1995; Pataki et al. 2005, 2006; Malek et al. 2006; Silcox et al. 2012). High particulate concentrations during CAPs have recently been linked to increased risk for cardiovascular disease and asthma and may lead to decreased lifespan (Pope et al. 2009; Beard et al. 2012). Suppressed temperatures within CAPs combined with the presence of snow cover can also increase the likelihood of fog, which affects air and ground transportation (Wolyn and McKee 1989).

The strength and longevity of persistent CAPs are modulated by the existing synoptic conditions, the surface energy budget, and subsequent interactions with advecting weather systems (Wolyn and McKee 1989; Whiteman et al. 1999, 2001; Reeves and Stensrud 2009; Gillies et al. 2010; Zardi and Whiteman 2013). CAPs most often form during the warming aloft accompanying the arrival of anticyclones. Weak disturbances may then temporarily perturb a CAP, whereas more vigorous baroclinic troughs are likely to completely destroy them, especially those accompanied by strong cold-air advection (Whiteman et al. 1999, 2001; Zhong et al. 2001; Reeves and Stensrud 2009; Zardi and Whiteman 2013).

In the absence of strong cold-air advection, forecasting the demise of CAPs remains a challenge. During such situations, CAP removal may be controlled by interactions among four other mechanisms: (1) dryconvection, (2) top-down turbulent erosion, (3) CAP displacement, and (4) airflow over the upstream topography (Lee and Pielke 1989; Petkovšek 1992; Petkovšek and Vrhovec 1994; Gubser and Richner 2001; Zängl 2003, 2005; Flamant et al. 2006).

In contrast to diurnal CAPs that form overnight and are destroyed by daytime heating, convection alone is generally insufficient to destroy persistent CAPs due to low sensible heat fluxes during the winter (Zhong et al. 2001). However, when other processes weaken a CAP, convection may become an important factor in its breakup (Whiteman et al. 1999; Zhong et al. 2001; Zardi and Whiteman 2013). For example, Whiteman et al. (1999) show that the final removal of persistent CAPs preferentially occurs in the afternoon when the sensible heat flux is greatest.

The second mechanism, turbulent erosion, is the break-down of CAP stratification via irreversible turbulent motions. Petkovšek (1992) proposed a semi-analytic model for this process wherein turbulent flow above a CAP progressively erodes downward into the stratified air. In this scenario, the depth of the CAP is progressively reduced, but the strength of the stratification within the capping layer increases in time. The increased capping-layer stratification subsequently suppresses the rate of turbulent encroachment, thus requiring an accelerating flow aloft for erosion to continue. Zhong et al. (2003) diagnose the timescale for turbulent CAP erosion using idealized CAP profiles and steady winds at different speeds. Their results show that the erosion rate decays in time, consistent with Petkovšek's hypothesis, and that turbulent erosion is very slow for typical CAP scales and thus unlikely to cause CAP break-up independent of other processes.

Turbulent erosion of stratification has also been observed in other geophysical flows, such as mixing across the thermocline in lakes and oceans (Fernando 1991). Strang and Fernando (2001a,b) use laboratory tank experiments to examine the deepening rate of a mixed layer into a stable layer and show that mixed-layer deepening progresses via Kelvin-Helmholtz and other dynamic instabilities, the occurrence of which is controlled by the Richardson number.

CAP displacement, the third process, is the re-arrangement of CAP mass via static and dynamic processes. Petkovšek and Vrhovec (1994), and later Zängl (2003), show that CAPs hydrostatically adjust to regional pressure gradients by developing a sloping interface and thus an internal pressure gradient that offsets the pressure gradient aloft. When the CAP slope becomes sufficiently large, cold air spills over the confining topography and the volume of 
air within the CAP is reduced (Zängl 2003). CAP tilt may also have a component due to wind stress acting on the CAP (Petkovšek and Vrhovec 1994; Gubser and Richner 2001; Zängl 2003). This effect can be particularly pronounced when winds are ageostrophic, e.g. acting in the same sense as the pressure gradient force (Zängl 2003). This wind-stress effect is similar to "wind set-up" or storm surge that displaces water along the downwind fetch within lakes.

CAP displacement may also occur due to airflow over the upstream topography. Lee and Pielke (1989) examine the interaction of a mountain wave with a lee-side CAP in idealized simulations, and show that the CAP is displaced by the mountain wave unless there is an adverse pressure gradient generating an opposing surface flow toward the mountain. Interestingly, they also found that turbulent erosion was a minimal factor in CAP evolution despite strong shear.

More generally, the ventilation of valleys containing stratified air masses has been related to the Froude number (or its inverse, the non-dimensional valley depth),

$$
F r=\frac{\bar{U}}{N H},
$$

where $\bar{U}$ is the mean wind speed above the valley, $N$ is the Brunt-Väisälä frequency, and $H$ is the valley depth (Bell and Thompson 1980; Tampieri and Hunt 1985; Lee et al. 1987). Bell and Thompson (1980) found that when $F r \geq 1.2$, the flow tends to sweep through a valley despite the stratification. Other studies have shown that, in addition to $F r$, the terrain geometry (including ridge spacing, slope angle, and the wavelength of lee waves) affects the character of the flow into the valley (Tampieri and Hunt 1985; Lee et al. 1987).

Relatively few observational studies have focused on the break-up of CAPs. Whiteman et al. (2001) document the differing destructive processes during two CAPs in the Columbia River Basin, one being affected by strong downslope winds and the other by cold-air advection and dry convection. Rakovec et al. (2002) examined turbulent processes during the break-up of CAPs in a Slovenian mountain valley. Using field observations and numerical experiments, they show that turbulent erosion commences above a threshold wind speed and continues if the flow accelerates. Flamant et al. (2006) examined the interaction of foehn winds with a CAP in the Rhine Valley during the Mesoscale Alpine Project. They conclude that CAP displacement along the valley axis is primarily caused by advection within the foehn flow, but also show that Kelvin-Helmholtz and gravity waves affect the CAP to a lesser degree.

In this study, we use data collected in the Salt Lake Valley of northern Utah during the Persistent Cold-Air Pool Study (PCAPS, Lareau et al. 2013) to examine the passage of a shortwave trough during a multi-day CAP. This trough-CAP interaction produced a variety of waves, displacement and fronts that disrupted the otherwise quiescent CAP. In the following sections we analyze the observed changes in CAP structure and develop a simple conceptual model for the trough-CAP interaction based on the observations and an idealized numerical simulation using a large-eddy simulation (LES) version of the Weather Research and Forecasting (WRF-LES) model (Skamarock et al. 2008).

\section{The Salt Lake Valley and Meteorological Data}

\subsection{The Salt Lake Valley}

The Salt Lake Valley, hereafter "the Valley", is located in northern Utah, USA at the eastern edge of the semi-arid Intermountain West, which is the region between the Sierra Nevada and Rocky Mountains. CAPs are common in the Valley during winter, affecting the nearly 


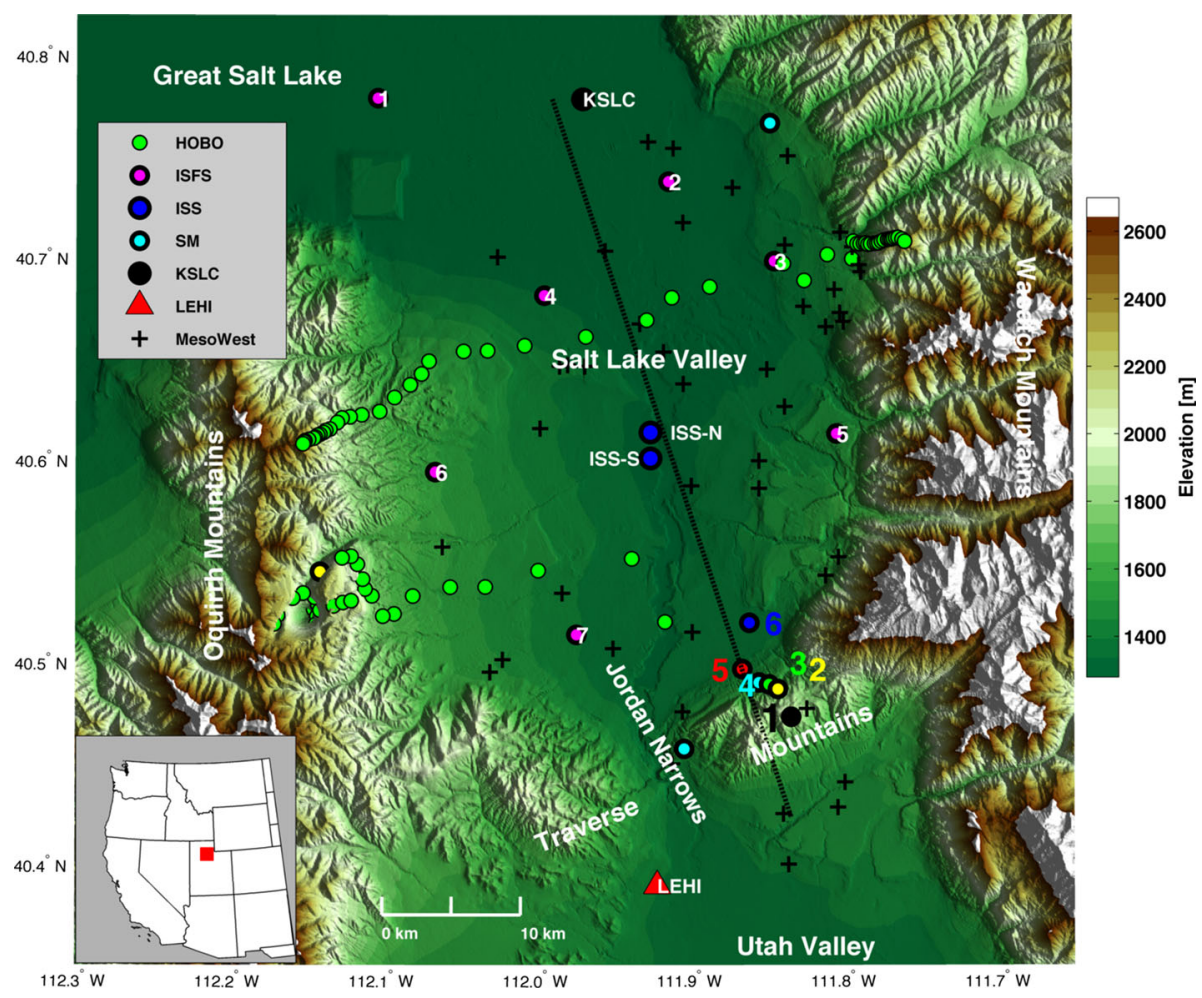

Fig. 1 Topographic map of the Salt Lake Valley, Utah showing instrument locations during the Persistent Cold-Air Pool Study. The inset shows the location of the Salt Lake Valley relative to the western USA. Further details are provided in the text

1 million residents. The meridionally oriented valley is confined to the east and west by the Wasatch (2,800 m) and Oquirrh (2,400 m) Mountains, respectively (Fig. 1). To the south, the Traverse Mountains $(1,800 \mathrm{~m})$, which have $500 \mathrm{~m}$ of relief, act as a partial barrier separating the Valley from the neighbouring Utah Valley. The Valley opens to the north-west into the Great Salt Lake Basin. The lowest elevations in the Valley are found along the Jordan River, which slopes downward from 1,400 $\mathrm{m}$ as it enters the Valley through the Jordan Narrows, a gap through the Traverse Mountains, to $1,280 \mathrm{~m}$ at the shore of the Great Salt Lake. East-west asymmetries in the Valley have large impacts during CAPs: (1) there is more landmass at a given elevation to the west of the Jordan River, and (2) north-south flow is blocked more to the east of the River than to its west.

\subsection{Meteorological Data}

The meteorological data used in this study were collected during the PCAPS Intensive Observing Period 1 (IOP-1). IOP-1 examined a multi-day CAP that formed on 1 December and lasted through 6 December 2010. We describe here the key observational resources that are used in this study, the locations of which are shown in Fig. 1. An overview of PCAPS and all available data resources are provided by Lareau et al. (2013).

To diagnose the evolution of the IOP-1 CAP, we construct time-height profiles of temperature, potential temperature, relative humidity, and wind intended to be representative of the conditions within the central core of the Valley. For this purpose, we rely most heavily 
on the data collected at the two (north and south) Integrated Sounding System (ISS) sites labeled by blue dots in Fig. 1, which are on bluffs immediately to the west of the Jordan River. A 915-MHz radar wind profiler (RWP) and Radio Acoustic Sounding System (RASS) were operated continuously at ISS-N, while radiosondes were launched at 3-12 h intervals from ISS-S, $1 \mathrm{~km}$ to the south, depending on the operational plan for the field program. We constrain these vertical profiles near the surface by automated weather observations at ISS-S and also use radiosonde data from the Salt Lake International Airport (KSLC; black dot in Fig. 1) above the boundary layer to improve the temporal coverage for periods when sondes were not launched at ISS-S. Gaps in the remote sensor data due to low signal-to-noise ratios are filled objectively using an "inpainting" analysis technique (Schönlieb 2012) and bounded by surface and radiosonde data at the gap boundaries. The resulting time-height profiles are quality controlled to remove spurious unphysical values and gradients and then averaged linearly with interpolated time-height profiles from the radiosonde data alone. The final set of time-height profiles reflect an effective blend of the remote sensor and in situ observations at a temporal interval of $30 \mathrm{~min}$ and a vertical resolution of $50 \mathrm{~m}$. These profiles are representative of the conditions throughout most of the Valley during this CAP except during the disturbance phase, described later, when these profiles reflect conditions near the ISS sites only.

A laser ceilometer located at ISS-S is used to characterize the mixing depth of aerosol, the presence of hydrometeors, and fine-scale structures within the boundary layer at 16-s temporal resolution (Young 2013). Two pseudo-vertical transects along the confining topography are created based on lines of near-surface sensors running up the sidewalls. The first transect is composed of six automatic weather stations (SM1-6) ascending the Traverse Mountains in the south-east corner of the valley with SM6 located on the valley floor at an elevation of 1,370 m while SM1 is on the Traverse Mountain ridgeline at an elevation of 1,930 m (see Fig. 1). These stations were equipped with wind, temperature, humidity and pressure sensors and recorded data every $5 \mathrm{~min}$. The second transect uses $\mathrm{HOBO}^{\mathrm{TM}}$ temperature data loggers aligned along Harker's Ridge, which is a sub-ridge along the east slope of the Oquirrh Mountains (northern string of green dots in Fig. 1). The HOBOs also report temperature every $5 \mathrm{~min}$. and are spaced vertically at 50-m intervals from 1,350 to 2,500 m.

Data from over 50 surface weather stations within the Valley with diverse suites of sensors are used from the Mesowest archive (Horel et al. 2002). In addition, seven 10-m Integrated Surface Flux System (ISFS) stations providing radiation, kinematic flux, and ground probe sensors as well as standard weather variables were deployed around the Salt Lake Valley as part of PCAPS (numbered in purple dots in Fig. 1).

\section{Results}

\subsection{IOP-1 Overview}

Wei et al. (2013) describe the conditions from 30 November to 7 December 2010 that encompass IOP-1 without relying on the PCAPS field campaign data, i.e., they examined KSLC radiosonde and Mesowest surface observations in combination with a WRF model simulation. Based on all the PCAPS data now available, we show that the IOP-1 CAP progressed through four stages in its life cycle: formation, disturbance, persistence, and break-up (Fig. 2). This paper primarily examines the disturbance phase, but here we briefly summarize the event in its entirety. 

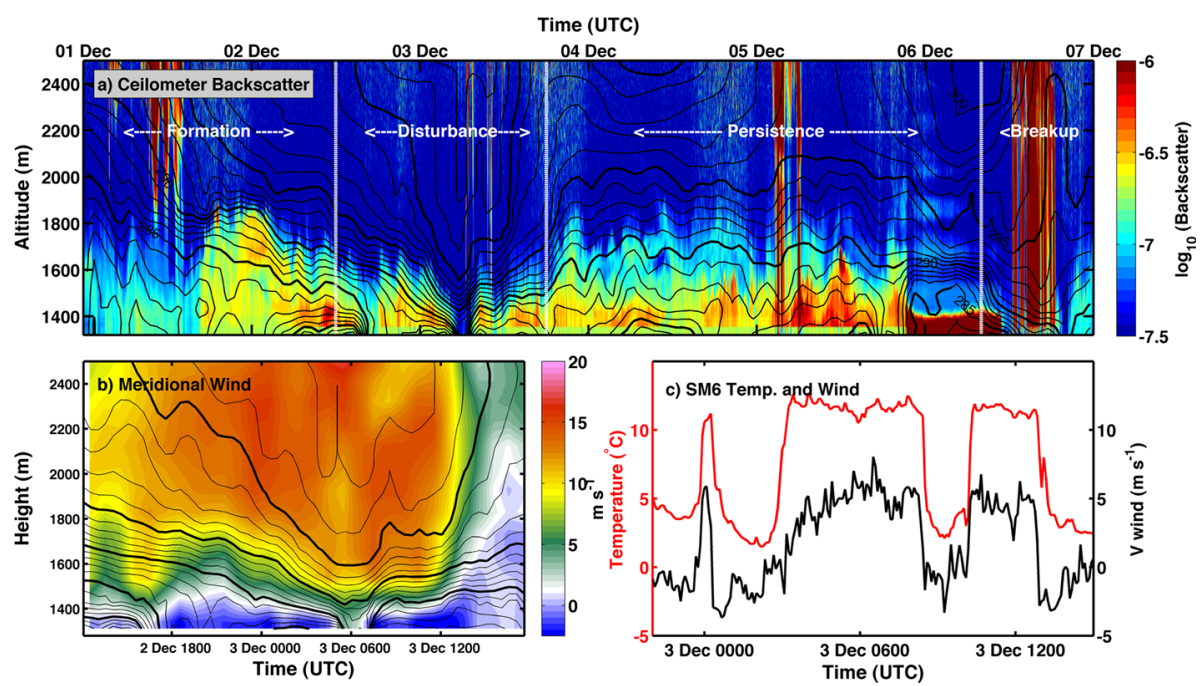

Fig. 2 Overview of PCAPS IOP-1. a Time-height profile at ISS-S of potential temperature (contours at 1 $\mathrm{K}$ interval) and aerosol backscatter (shading) where yellow-orange (blue) shades reflect high (low) aerosol concentrations and dark red shades denote hydrometeors. b Time-height profile of meridional wind (shading) and potential temperature during the disturbance phase. c Surface temperature and meridional wind at SM6, which is located at the base of the Traverse Mountains in the south-east corner of the Salt Lake Valley

\subsubsection{Formation}

The IOP-1 CAP followed the passage of a strong shortwave trough, which brought snow and low temperatures to the Valley. The CAP was then initiated by mid-tropospheric ridging and warming, which formed a capping layer of strong static stability that decoupled the cold valley atmosphere from the flow above crest level (Wei et al. 2013).

The strength of the nascent CAP was subsequently augmented by a surface-based radiation inversion forming during clear skies overnight on 2 December. Averaged over the seven ISFS stations, the net radiative cooling in the valley on that night is the strongest during the CAP episode (not shown). Combined, the warming aloft and cooling at the surface yielded a $700 \mathrm{~m}$ deep CAP with a surface potential temperature deficit (relative to that near the top of the CAP) in excess of $15 \mathrm{~K}$ at 1200 UTC 2 December. Weak winter insolation, high albedo due to snow cover, and the strong stability suppressed the growth of the convective boundary layer the following afternoon, which allowed the CAP to persist and for aerosol to accumulate rapidly (Fig. 2a). Concentrations of aerosol particulates with diameters $<2.5 \mu \mathrm{m}\left(\mathrm{PM}_{2.5}\right)$ surpassed the National Ambient Air Quality Standard (U.S. EPA 2013) of $35 \mu \mathrm{g} \mathrm{m}^{-3}$ after just the second day of the cold pool (not shown).

\subsubsection{Disturbance}

The disturbance phase of IOP-1 occurred on 3 December as the initial ridge moved downstream and a weak shortwave trough accompanied by mid-level clouds moved across the Intermountain West (not shown). The approaching trough generated a compact regional pressure gradient that accelerated southerly flow above the CAP, reaching a peak meridional speed of $15 \mathrm{~m} \mathrm{~s}^{-1}$ during the early morning of 3 December (Fig. 2b). Terrain channeling controlled the orientation of the flow in the Valley, leading to ageostrophic southerly flow 
oriented along the valley axis and down the regional pressure gradient. As the wind speed increased aloft, the CAP thinned from approximately $700 \mathrm{~m}$ at 0000 UTC 2 December to $150 \mathrm{~m}$ at 0600 UTC 3 December (Fig. 2a, b). The downward slope of the isentropes within the capping layer of strong static stability is partially due to increased warm air advection and, as we show later, also due to tilting and displacement of the CAP.

Surface conditions at station SM6 on the valley floor at the extreme southern end of the Valley and immediately in the lee of the Traverse Mountains (Fig. 2c) remained quiescent (speeds less than $3 \mathrm{~m} \mathrm{~s}^{-1}$ ) and were similar to those observed throughout most of the Valley until 0000 UTC 3 December at which time the first burst of warm $\left(>10^{\circ} \mathrm{C}\right)$ and windy (speeds greater than $7.5 \mathrm{~m} \mathrm{~s}^{-1}$ ) conditions penetrated for a brief time to the surface. CAP conditions resumed at this location until 0300 UTC followed by a second intrusion of warm, dry, windy conditions through 0830 UTC (Fig. 2c). Another short period of CAP conditions was followed by the third warm, windy burst from 1000-1300 UTC. The causes for these abrupt changes in surface conditions are explored hereafter.

The disturbance period in the Valley concludes after 1500 UTC 3 December as the trough axis passes over the region bringing a sharp reduction in the wind speed aloft and surface conditions at the south end of the valley return roughly to those observed the day before. Hence, the disturbance period is more complex than the hypothesis provided by Wei et al. (2013) that it was due to the passage of a weak cold front.

\subsubsection{Persistence}

Following the trough's departure, the CAP returns to a quiescent state, providing continued low temperatures and high levels of pollution as ridging builds over the Intermountain West on 4-6 December (Fig. 2a). During this phase, the CAP eventually developed a stratocumuluscapped boundary layer and periods of surface fog (red shading Fig. 2a).

\subsubsection{Break-up}

The IOP-1 CAP was terminated late on 6 December by cold-air advection aloft, convection, and increased wind speeds associated with a stronger shortwave trough moving into the region (Wei et al. 2013). The breakup of the valley stratification was accompanied by a reduction in the particulate pollution and a return to improved air quality (not shown).

\subsubsection{Forecast Uncertainty}

During this CAP event, forecasting the extent of the trough-CAP interaction on 3 December was particularly difficult. Operational and research numerical weather prediction guidance did not resolve the details associated with this weak trough passage and the limited impact it had on improving air quality in the Valley. For example, while the retrospective research simulations completed by Wei et al. (2013) captured many of the general features associated with IOP-1, their simulation fared poorly during the disturbance phase with wind speed and direction errors as large as $10 \mathrm{~m} \mathrm{~s}^{-1}$ and $90^{\circ}$ respectively, and temperature errors greater than $2.5^{\circ} \mathrm{C}$ below $700 \mathrm{hPa}$. To better understand the unresolved processes that contributed to the CAP evolution during the disturbance phase, we now turn to detailed analyses of PCAPS observations. 

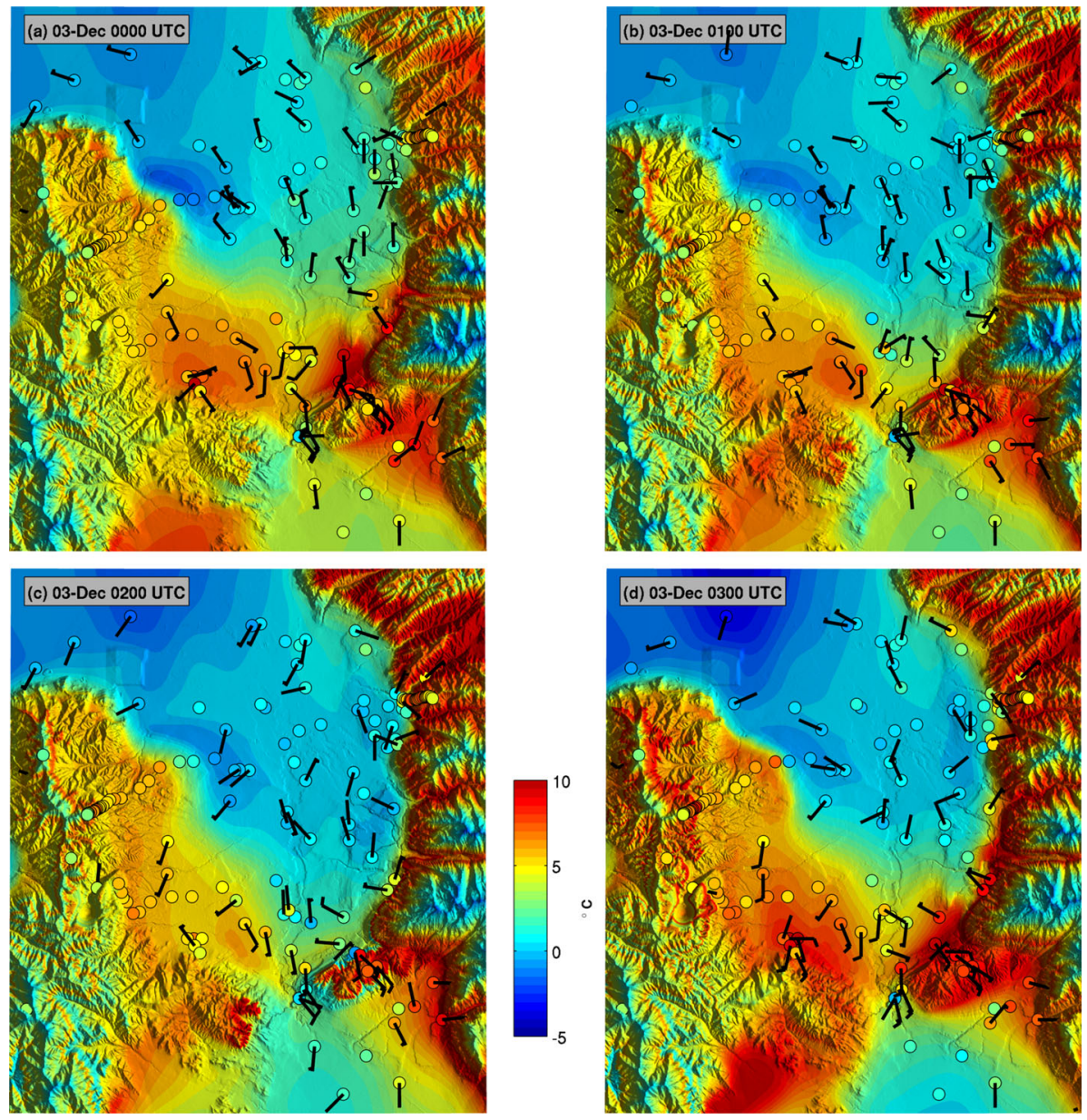

Fig. 3 Hourly surface temperature analyses (colour shaded) from 0000-0300 UTC 3 December 2010. Surface temperature observations (filled circles shaded according to the scale) and vector wind (wind barbs in $\mathrm{m} \mathrm{s}^{-1}$ where a full barb denotes $5 \mathrm{~m} \mathrm{~s}^{-1}$ )

\subsection{Surface Temporal Evolution}

The abrupt changes in surface meteorological conditions evident in Fig. 2c are caused by a sequence of displacements of the CAP along the Valley axis. To better understand these displacements, hourly surface temperature analyses at 100-m horizontal resolution are created from all available surface temperature observations using a Barnes horizontal and vertical distance weighting (Barnes 1964) of the departures of the observed temperatures from the temperature estimated for that elevation from the hourly profiles of temperature described in Sect. 2.2 (Figs. 3, 4, 5, 6). The horizontal e-folding radius is 20, 10, and $5 \mathrm{~km}$ for three successive iterations of the analysis cycle. The vertical radius is held constant at $75 \mathrm{~m}$. Variations in the e-folding radii alter the fine scale structure (e.g. fronts) in the analyses but do not substantively alter the interpretation of the results. The relatively dense network of temperature observations available in the Valley during this IOP reduces the sensitivity of 

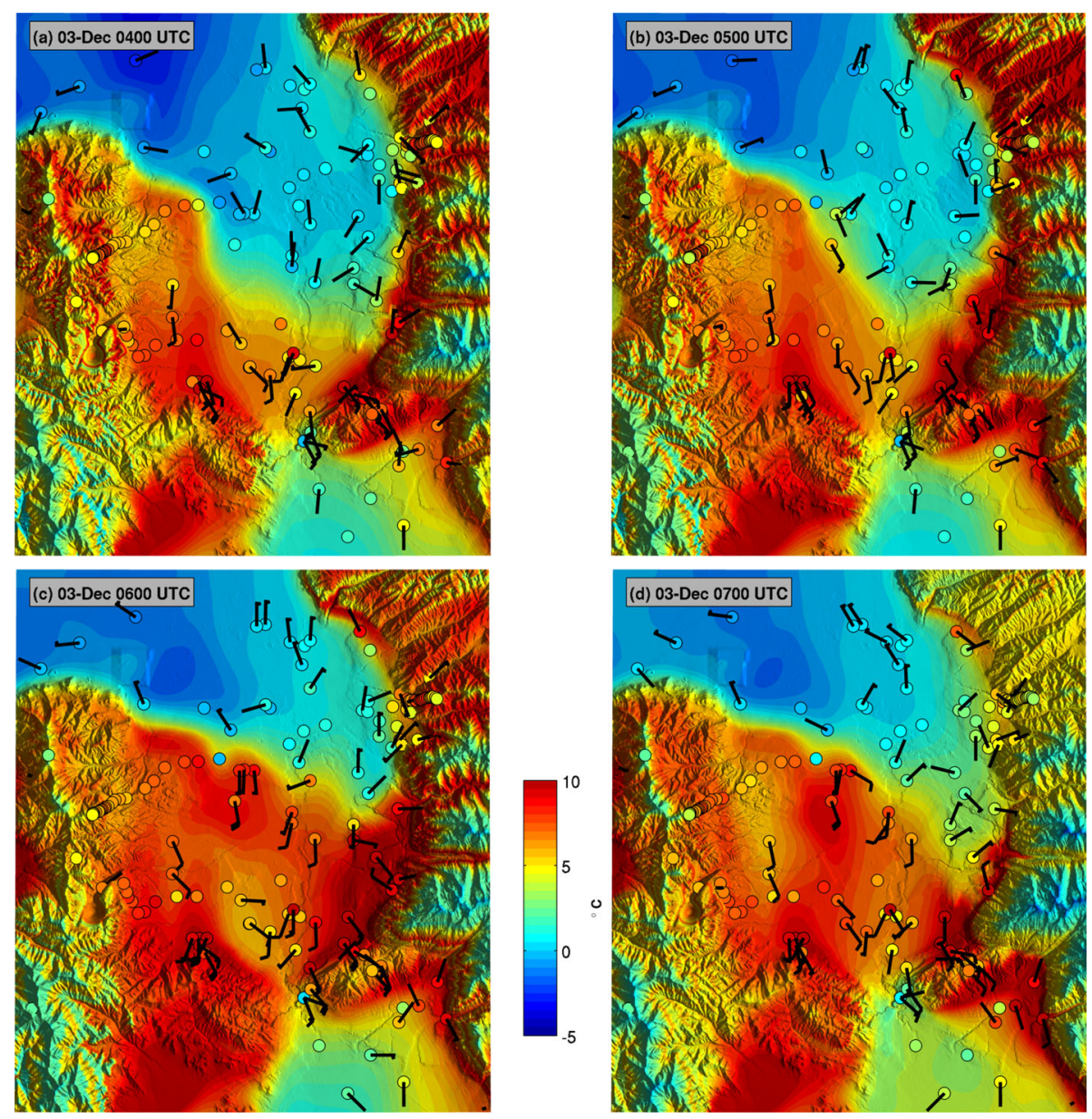

Fig. 4 As in Fig. 3 except for 0400-0700 UTC 3 December

the resulting analyses to the technique, e.g., very similar temperature analyses have been obtained for this period using a two-dimensional variational analysis technique (Tyndall and Horel 2013).

The overall dependence of temperature on elevation is immediately apparent from the surface temperature observations and analyses in Figs. 3, 4, 5 and 6. For example, the string of HOBO temperature sensors along Harker's Ridge (Fig. 1) at 0000 UTC (Fig. 3a) show a change from low temperatures (blue shades) in the valley to much higher temperatures on the western slopes of the valley (yellow and orange shades) before again decreasing at the upper reaches of the Oquirrh Mountains (blue shades). Prior to 0000 UTC, the temperatures in the lowest elevations of the Valley were nearly uniform (not shown).

The first CAP displacement in the Valley is evident at 0000 UTC when the leading edge of the CAP shifts northward, forming an east-west frontal zone (Fig. 3a). Warm air $\left(5-10{ }^{\circ} \mathrm{C}\right)$ and southerly flow penetrate to the surface to the south of the front, while cold air $\left(0^{\circ} \mathrm{C}\right)$ and northerly flow are present to the north. This initial CAP displacement is reversed over the next $2 \mathrm{~h}$ (Fig. $3 \mathrm{~b}, \mathrm{c}$ ) as the CAP edge advances southward at the lowest elevations, eventually 

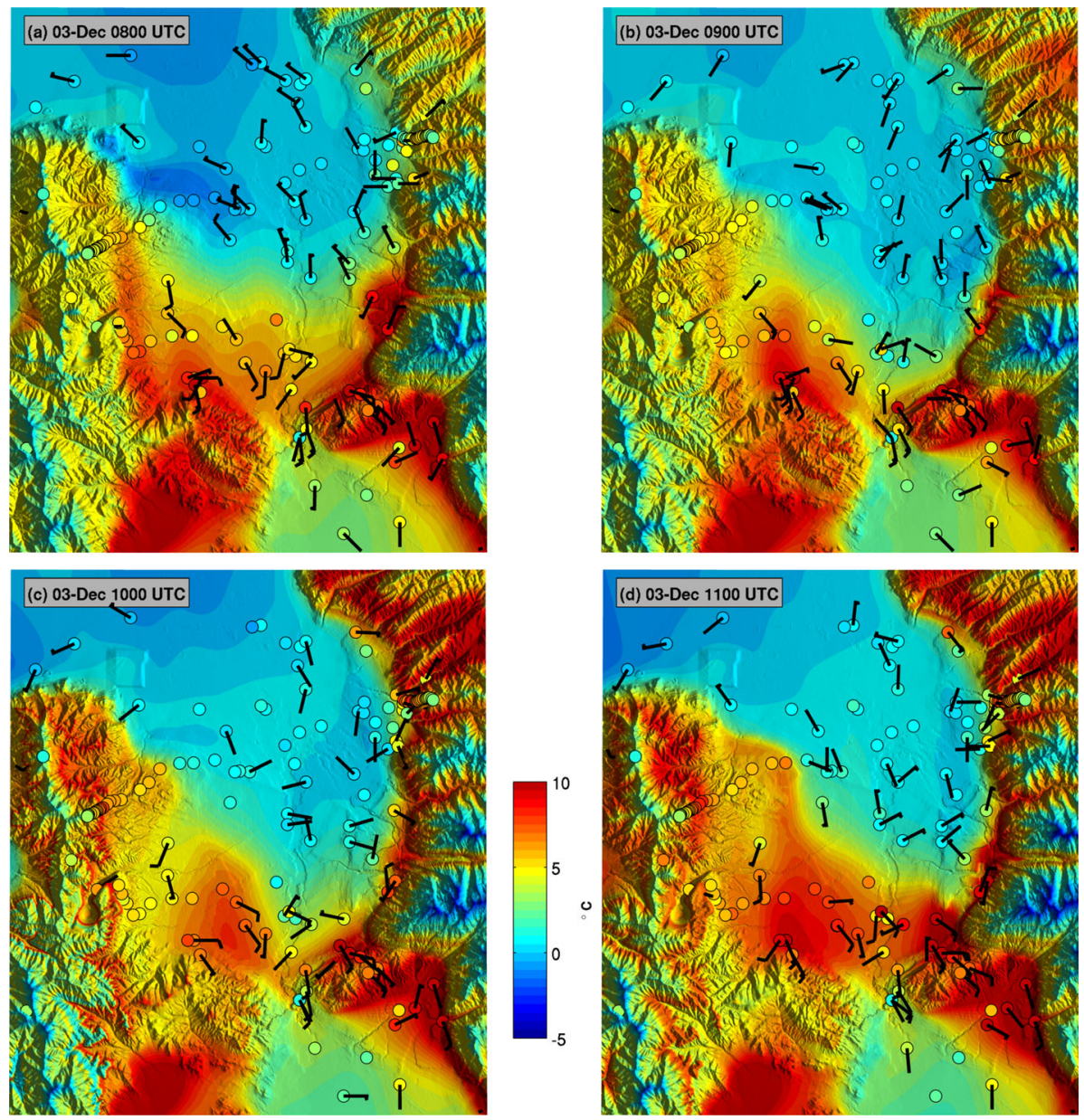

Fig. 5 As in Fig. 3 except for 0800-1100 UTC 3 December

abutting the Traverse Mountains to the east of the Jordan Narrows. The south-west corner of the Valley remains out of the CAP at that time with southerly flow continuing over the Traverse Mountains in that region.

A second northward CAP displacement is initiated at 0300 UTC as strong winds and higher temperatures again surface along the south-eastern portions of the Valley (Fig. 3d). The southerly flow is particularly strong and warm along the lee slopes of the Traverse Mountains. The edge of the CAP then moves progressively northward through the Valley, reaching its northernmost excursion at 0600 UTC (Fig. $4 \mathrm{a}-\mathrm{c}$ ). High temperatures $\left(10^{\circ} \mathrm{C}\right)$ and strong southerly winds $\left(7-10 \mathrm{~m} \mathrm{~s}^{-1}\right)$ are reported at that time throughout the southern two thirds of the Valley, while light winds and temperatures around $0{ }^{\circ} \mathrm{C}$ persist within the displaced CAP. Adjacent temperature observations indicate that the temperature gradient across the leading edge of the $\mathrm{CAP}$ is as much as $7-10^{\circ} \mathrm{C}$ over $2 \mathrm{~km}$ in some places. The pronounced tendency for the displacement of the CAP to be enhanced over the western portion of the Valley arises in part from its higher elevation as well as the unimpeded flow towards the Great Salt Lake on that side of the Valley. 

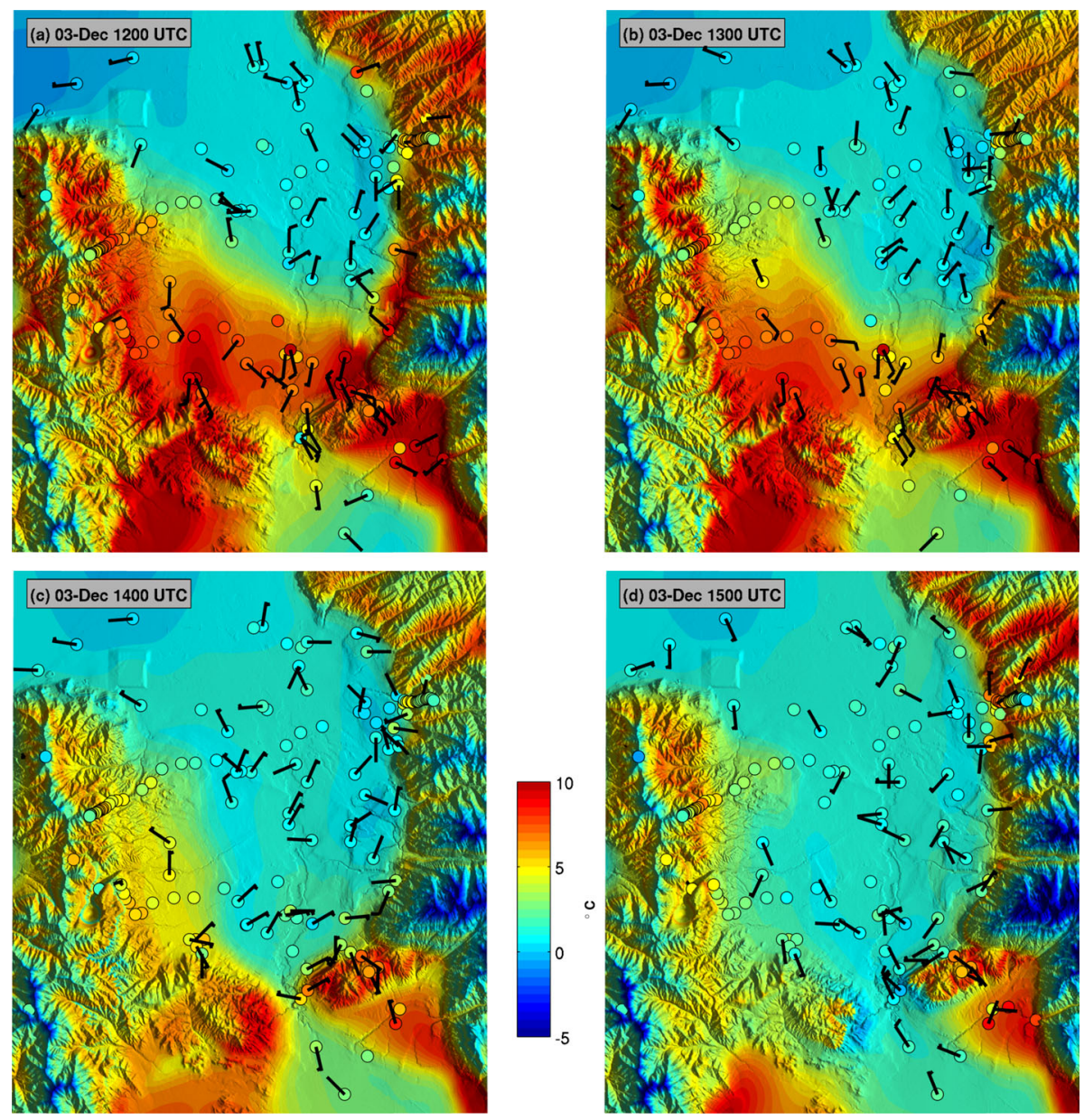

Fig. 6 As in Fig. 3 except for 1200-1500 UTC 3 December

Despite continued strong southerly flow aloft, the leading edge of the CAP again reverses course between 0700 and 0800 UTC, returning southward through the Valley (Figs. 4d, 5a). As the cold air advances, winds to the north of the front become coherent in strength and direction, flowing from the north-west to south-east then turning south along the valley axis (Fig. 5a). Meanwhile, strong south winds continue to the south of the front indicating convergence along the leading edge of the cold air. As the CAP envelops observing sites throughout the Valley, the cold frontal temperature fall is nearly identical in magnitude to the previous warm frontal rise, which produces the step changes apparent in individual time series (e.g., Fig. 2c). By 0900 UTC (Fig. 5b), the cold front encroaches on the Traverse Mountains in the south-eastern sections of the Valley. As before, high temperatures and strong winds continue along the south-western portion of the valley and near the crest of the Traverse Mountains.

The third and final CAP displacement commences between 1000 and 1200 UTC as the frontal boundary again moves northward re-establishing a position across the valley centre (Figs. 5c, d, 6a). This third displacement is shorter lived, and as the winds aloft diminish after 

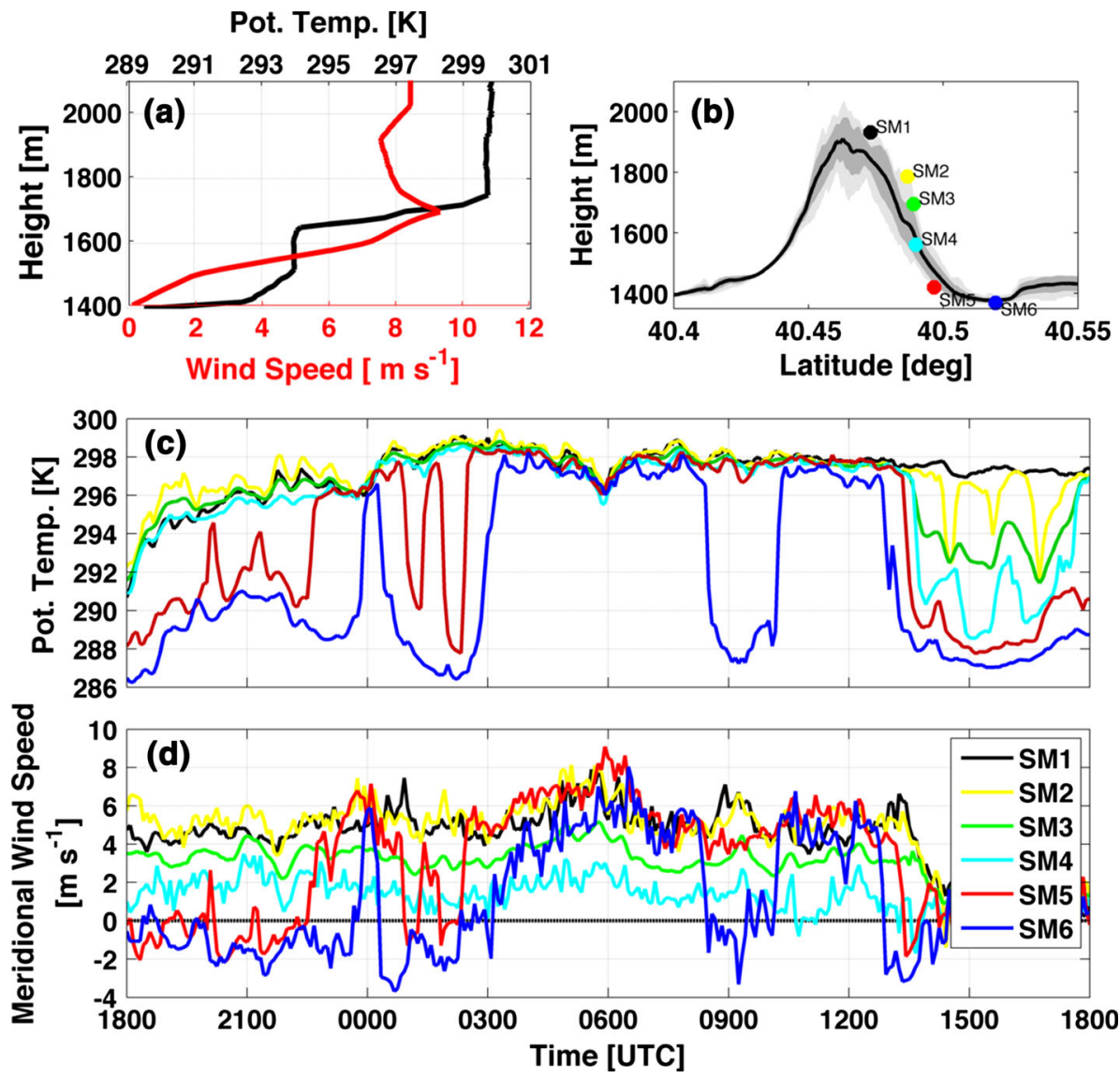

Fig. 7 Properties of the mountain wave forming over the Traverse Mountains. a Sounding upstream of the Valley at Lehi, Utah at 0600 UTC 3 December showing potential temperature (black) and meridional wind (red). b Traverse Mountain cross-section showing station locations and the terrain variability (shading). c Potential temperature and $\mathbf{d}$ meridional wind time series for each of the six SM stations

1200 UTC (Fig. 2b), the cold front mobilizes southward for the final time (Fig. 6b). By 1500 UTC (Fig. 6d), the CAP has returned throughout the Valley and penetrates south through the Jordan Narrows into the neighbouring Utah Valley. This reversal in the gap flow effectively marks the end of the disturbed CAP conditions and a return to the quiescent and horizontally homogenous CAP ensues.

\subsection{Mountain Wave}

The north-south displacements of the CAP evident in the hourly surface temperature analyses and other earlier figures result in part from the southerly flow crossing over the Traverse Mountains into the Valley. The vertical profiles of potential temperature and wind speed upstream of the Traverse Mountains at Lehi, UT (red triangle in Fig. 1) are shown at 0600 UTC 3 December in Fig. 7a, which corresponds to the time of the furthest northward displacement of the CAP. The profiles suggest upstream conditions can be characterized at that time as a two-layer stably-stratified fluid: nearly constant wind speed and potential temperature above 
1,750 $\mathrm{m}$ with $6 \mathrm{~K}$ lower potential temperature below 1,650 $\mathrm{m}$ with increasing wind speeds through the lower layer and extending into the intervening strong stable layer.

Ignoring the surface-based inversion, which reflects local conditions at the observation site, it is possible to compute the internal Froude number from this profile as

$$
F r=\frac{\bar{U}}{\sqrt{g^{\prime} h}},
$$

where $\bar{U}$ is the mean wind speed $\left(6 \mathrm{~m} \mathrm{~s}^{-1}\right), h$ is the height of the interface $(300 \mathrm{~m})$ and,

$$
g^{\prime}=\frac{\Delta \theta}{\bar{\theta}} g
$$

is the reduced gravity where $\Delta \theta$ is the change in temperature across the capping layer $(6 \mathrm{~K})$ and $\bar{\theta}$ is the mean profile temperature $(297 \mathrm{~K})$. With these approximations $F r \approx 0.8$, indicating that the upstream mean flow is less in speed than the fastest linear shallow water gravity waves. It is likely that as the flow passes over the crest of the Traverse Mountains and thins (e.g., $h$ reduced to $100 \mathrm{~m})$ it changes to a super-critical state $(F r>1)$. Following the hydraulic flow analogy, such a flow is expected to produce a mountain wave with strong downslope winds with non-linear effects including a downstream hydraulic jump (Durran 1986). Similar flows have previously been documented over the Traverse Mountains during diurnal CAPs by Chen et al. (2004).

The impact of the mountain wave along the fall line of the Traverse Mountains is shown in Fig. 7c. Consider first the conditions at the time of the upstream sounding (0600 UTC). All stations from the ridge crest (SM1) to the valley floor in the lee (SM6) report the same potential temperature, $297 \mathrm{~K}$, which is consistent with air in the upstream stable layer at $1,700 \mathrm{~m}$ being lifted up and over the ridge. Wind speeds at the crest (SM1-black curve) and near the valley floor (SM5—red; SM6 — dark blue respectively) are equally strong at this time and occasionally the winds at the base of the slope are stronger, reflecting acceleration of the flow. (Consistently weaker winds at intervening sites, such as SM4, light blue curve, reflect siting more than atmospheric conditions.)

The pulsing of mountain waves throughout the disturbance phase causes the along-slope potential temperature profile to abruptly switch between stratified and adiabatic states (Fig. 7c). For example, the ridge-to-valley potential temperature difference is about $12 \mathrm{~K}$ at 0250 UTC, whereas just 20 min later it is nearly zero (the wind and temperature traces at SM6 in Fig. 2c are repeated as the blue curves in Fig. 7 c, d). Periods of along-slope adiabatic flow are accompanied by the penetration of strong southerly winds to the valley floor, whereas weak northerly flow near the valley floor coincides with stratification. The re-stratification of the CAP once the southerly flow lessens is clearly evident after 1300 UTC with no change in the conditions at the top (SM1) and progressively lower potential temperatures down the lee slope into the valley.

To visualize in greater detail the impact of the flow across the Traverse Mountains, an idealized LES is shown in Fig. 8. The simulation is initialized from temperature and wind profiles similar to those shown in Fig. 7a and uses a 50-km cross-section of the Valley beginning south of the Traverse Mountains, extending north across the ISS sites, and terminating at the Salt Lake International Airport (dashed black line, Fig. 1). The model domain is $1 \mathrm{~km}$ wide to allow three-dimensional turbulence and uses open boundary conditions at the downwind (northern) boundary and a Rayleigh damping layer at the southern boundary that maintains a constant inflow profile. The ridge topography varies slightly in the spanwise direction to help generate three-dimensional flow. The near-surface inversion in the upstream sounding 

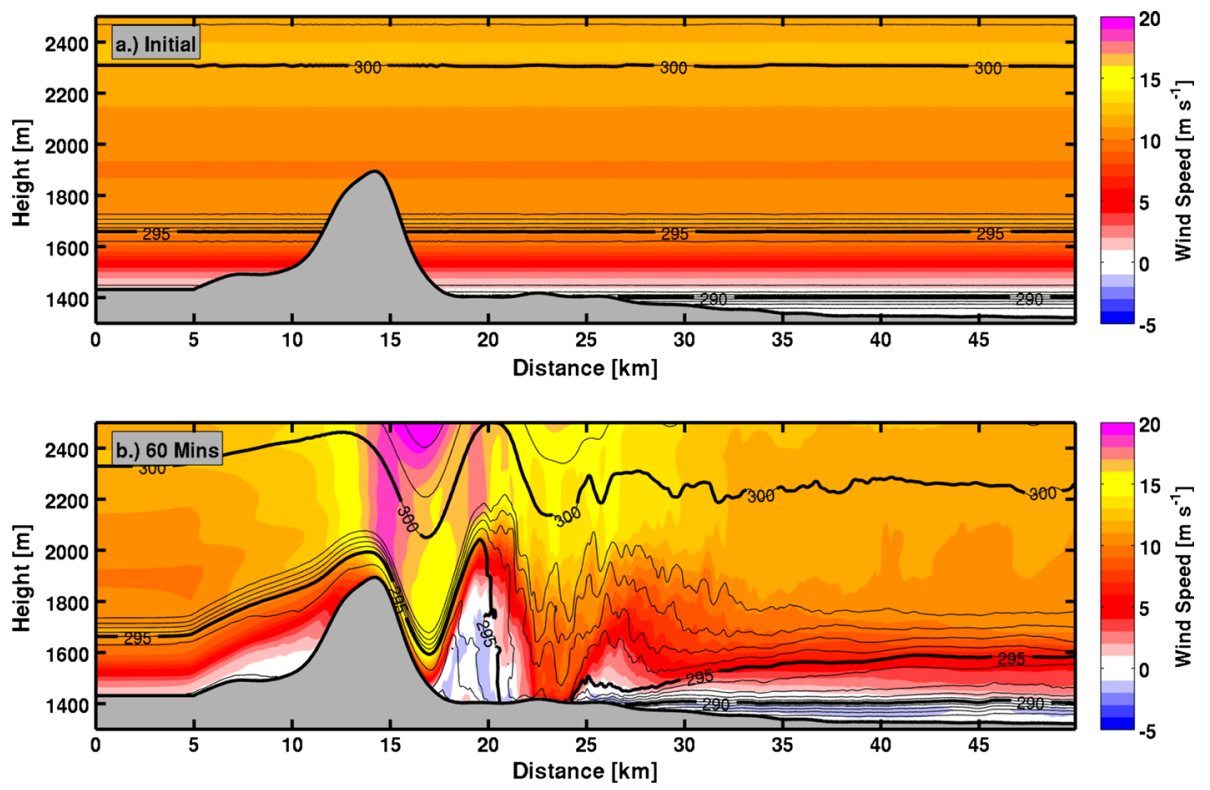

Fig. 8 Large-eddy simulation of a mountain wave disrupting the two-layered CAP. Panels show wind speed (colours) and potential temperature (contours, bold every $5 \mathrm{~K}$ ) at a the initialization and $\mathbf{b}$ after $1 \mathrm{~h}$ of simulation. The terrain cross-section is along the black line if Fig. 1, with north to the right

is extrapolated to match the observed surface temperature ISS-S within the Valley, which was $285 \mathrm{~K}$. Radiation is neglected, as are sensible heat fluxes at the surface, and friction is parametrized using a Monin-Obukov surface-layer scheme. The horizontal grid spacing is 50 $\mathrm{m}$ and there are 100 vertical levels stretched over $10 \mathrm{~km}$. The vertical resolution is nominally $30-50 \mathrm{~m}$ within the valley. The simulation is run for $1 \mathrm{~h}$ to capture the immediate response of the downstream CAP to the upstream-stratified flow over the topography.

After $1 \mathrm{~h}$, a pronounced mountain wave, hydraulic jump, and CAP displacement are apparent (Fig. 8b). The low-level upstream flow is partially blocked such that the depth of the cold lower layer increases until it surmounts the ridge and spills down the lee slopes. As we speculated above, the Froude number at the mountain crest exceeds the critical value within the overtopping flow. The flow aloft behaves similarly, represented by perturbations in the height of the $300 \mathrm{~K}$ isentrope. Accompanying the thermal perturbation of the wave is a marked increase in wind speed above the ridge crest and extending down the lee slope. The lee-side along-slope flow is ostensibly adiabatic with constant speed in excess of $10 \mathrm{~m} \mathrm{~s}^{-1}$, consistent with observations in Fig. 7c,d.

The flow separates from the surface near the base of the lee slope in a pronounced hydraulic jump. The presence of the upstream inversion layer is well known to favour such hydraulic jumps, lee waves, and boundary-layer separation (Vosper 2004; Jiang et al. 2007). The surface flow within the jump region is reversed and the air becomes turbulently mixed, reducing the stratification and eroding the surface-based inversion. Consequently a front forms separating the comparatively quiescent near-surface CAP conditions to the north from the better mixed and windier conditions to the south.

The front shown in the numerical simulations suggests a link between the mountain wave and the CAP advance and retreat throughout the valley. For example, the northward CAP 


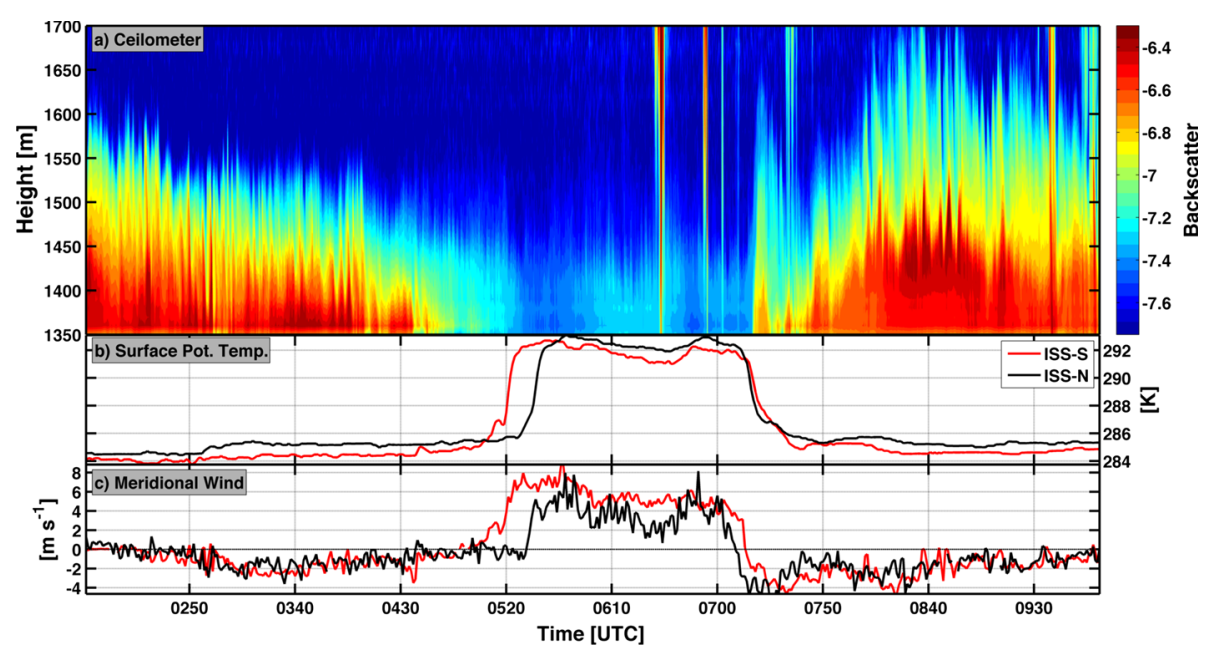

Fig. 9 Time series data during the warm and cold frontal passages at ISS-S and ISS-N on 3 December 2010. a Laser ceilometer backscatter, $\mathbf{b}$ potential temperature, and $\mathbf{c}$ meridional wind-speed component

displacement between 0300 and 0600 UTC corresponds with increased downslope flow, whereas the frontal reversal is linked with a modest decrease in the downslope wind speeds. However, since the mountain wave remains fixed to the topography, additional factors must contribute to the larger displacement of the CAP throughout the valley.

\subsection{Advance and Retreat of the CAP}

While the mountain waves caused the CAP to retreat and advance in the extreme southeastern end of the Valley three times on 3 December, a single disruption of the CAP was centred near 0600 UTC 3 December at the ISS sites. Figure 9 shows in more detail this 3-h period when the CAP retreated northward past the ISS sites temporarily providing clean air (low aerosol backscatter). The retreat of the CAP is synonymous with the passage of a warm front, which is marked by a gradual reduction in the height of the aerosol layer followed by rapid reduction in aerosol concentration (Fig. 9a), a $7 \mathrm{~K}$ temperature rise (Fig. 9b), and a burst of strong southerly winds at the surface (Fig. 9c). As the front continues northward past ISS-S, there is a 12-min lag before its passage at ISS-N, which is $1 \mathrm{~km}$ away, giving a propagation speed of $1.5 \mathrm{~m} \mathrm{~s}^{-1}$. Using these values, the width of the frontal zone is about $1 \mathrm{~km}$ and the front-normal temperature gradient is then $7 \mathrm{~K} \mathrm{~km}^{-1}$. The wind speeds on the warm side of the front are around $8 \mathrm{~m} \mathrm{~s}^{-1}$ from the south while those within the CAP are nearly zero.

In contrast to the gradual thinning and quiescent prefrontal conditions associated with the warm front, the cold front arrives with strong northerly flow (4-5 m s${ }^{-1}$ ) and an abrupt $200 \mathrm{~m}$ increase in the depth of the aerosol layer (Fig. 9a). This frontal "head" is shown in more detail in Fig. 10 and moves more quickly than the warm front, advancing between the ISS sites in just $5 \mathrm{~min}$, giving a propagation speed of $3.5 \mathrm{~m} \mathrm{~s}^{-1}$, which is more than twice that of the warm front. The northerly flow within the cold air behind the front combined with the opposing southerly flow of 5-7 $\mathrm{m} \mathrm{s}^{-1}$ implies strong convergence.

In the wake of the frontal head, the aerosol-layer depth decreases and high amplitude waves develop (Fig. 10). This morphology is consistent with the characteristics of an advancing 


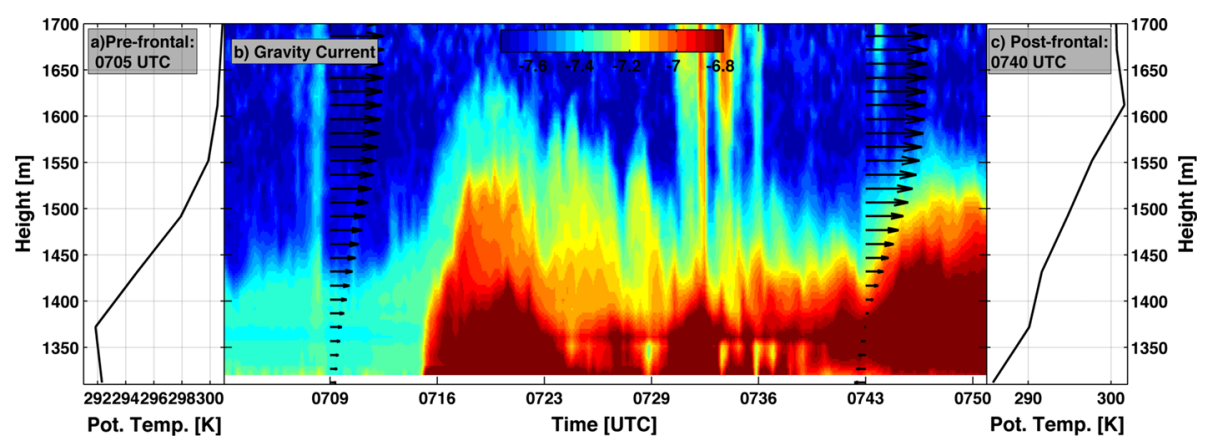

Fig. 10 Detail of the gravity current passage at ISS-S. a Potential temperature profile at 0705 UTC preceding the cold frontal passage, $\mathbf{b}$ ceilometer backscatter and meridional wind profiles from the radar wind profiler, and c post cold frontal potential temperature profile at 0740 UTC. Profile data are retrieved from the time-height dataset

gravity current, e.g. an elevated head, convergent opposing flow, and mixing via KelvinHelmholtz waves behind the front (Simpson 1997). Moreover, the ceilometer data suggest that the upstream stratified air mass with low aerosol backscatter is lifted over the gravity current head, with evidence of the frontal disturbance reaching as high as $300 \mathrm{~m}$ a.g.l. (Fig. 10). This evolution closely resembles laboratory and numerical simulations of gravity currents propagating into a two-layer stratified environment (Simpson 1997; White and Helfrich 2012). In this case the advance of the gravity current is an important mechanism for restoring the cold-air pool conditions throughout the valley by allowing the cold air to propagate against the ambient southerly flow aloft.

\subsection{CAP Tilt}

The displacements of the CAP described in the previous sections are accompanied by variations in the along-valley slope of the CAP. As the CAP retreats to the north it exhibits a significant northward incline (e.g. deeper cold air to the north) whereas the southward cold frontal advances correspond to a more horizontally homogenous state. An example of the tilted CAP is provided in Fig. 11, which contrasts the vertical profiles of potential temperature and wind over a distance of $19.2 \mathrm{~km}$ between ISS-S and KSLC near the end of the disturbance phase (1115 UTC). The depth of the CAP at KSLC is clearly $200 \mathrm{~m}$ deeper than at ISS-S, and thus about $400 \mathrm{~m}$ deeper than at the leading edge of the CAP, which is about $3 \mathrm{~km}$ south of ISS-S at this time. The CAP top is identified by the transition to an adiabatic profile aloft (Fig. 11a) and the height of the jet maximum in the meridional wind (Fig. 11b).

The corresponding pressure gradient between the two soundings is shown in Fig. 11c. Above the CAP the pressure gradient is oriented from north to south (e.g. low pressure to the north), consistent with the approaching shortwave trough. The magnitude of the horizontal pressure gradient aloft $\left(1.25 \times 10^{-3} \mathrm{~Pa} \mathrm{~m}^{-1}\right)$ matches the value obtained from re-analysis data at 1200 UTC (not shown). The strong southerly flow $\left(15 \mathrm{~m} \mathrm{~s}^{-1}\right.$ ) above the CAP is predominately ageostrophic, reflecting pressure channeling within the Valley. Within the CAP the pressure gradient is reversed with higher pressure over the northern portion of the valley due to the deeper cold air there. Weak northerly flow is evident only near the surface while the winds in the upper layers of the CAP remain from the south and against the pressure gradient. 

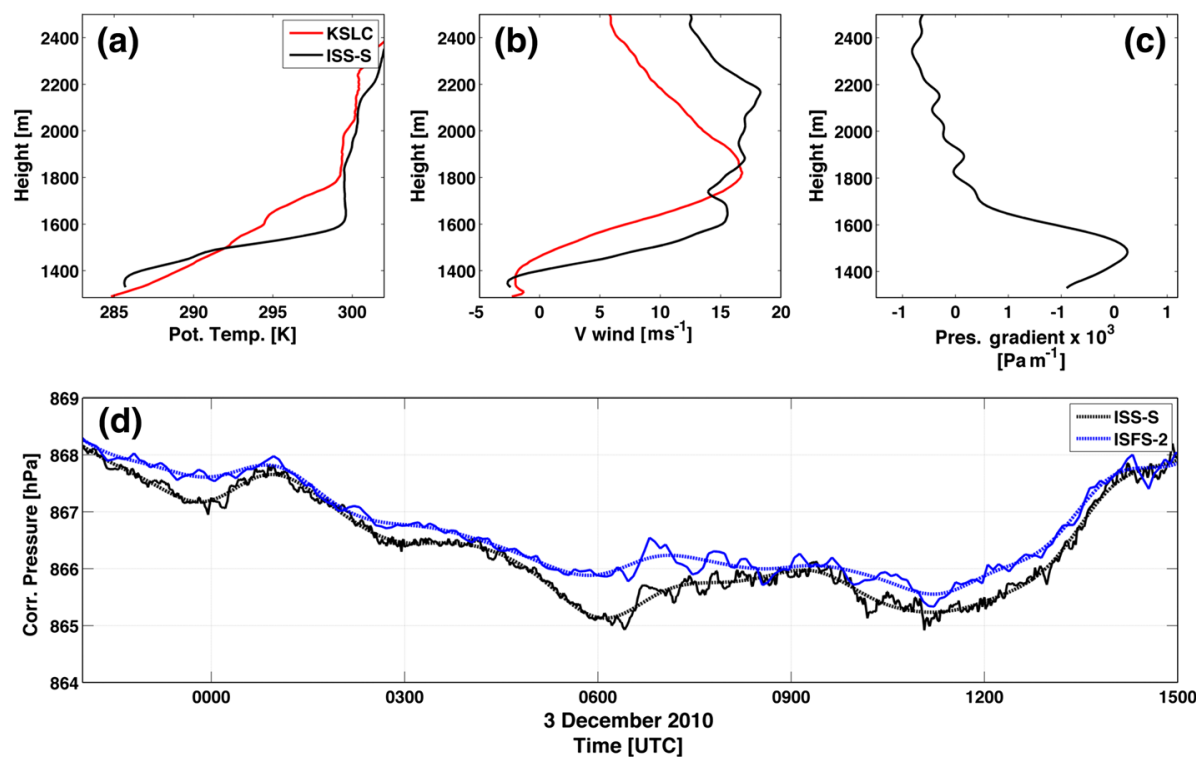

Fig. 11 Vertical profiles of a potential temperature and b meridional wind launched at 1115 UTC at KSLC (red lines) and ISS-S (black lines). $\mathbf{c}$ The pressure gradient between KSLC and ISS-S. d Time series of elevation corrected surface pressure for ISS-S (black) and ISFS-2 (blue). The raw and smoothed data are shown for each site

The force balance maintaining the observed CAP tilt is examined by representing the CAP as a two-layered shallow-water system beneath a rigid upper lid. The lower layer, the CAP, has a density $\left(\rho_{2}\right)$ greater than that of the layer aloft $\left(\rho_{1}\right)$ and the lid applies a pressure gradient $(\partial P / \partial x)$ to the system as a whole, representative of the synoptic-scale pressure gradient aloft. If we assume the lower layer is at rest while the upper layer moves downstream at a speed $U_{1}$, then the steady-state non-rotating momentum equation for the lower layer can be written as

$$
\frac{\partial H}{\partial x}=-\frac{1}{\rho_{1} g^{\prime}} \frac{\partial P}{\partial x}+\frac{C_{d} U_{1}^{2}}{g^{\prime} \bar{H}},
$$

where $H$ is the height of the interface (e.g. the CAP top), $g^{\prime}=\frac{\left(\rho_{2}-\rho_{1}\right)}{\rho_{1}} g$ is the reduced gravity, $C_{d} U_{1}^{2}$ is the parametrized shear stress between layers using a drag coefficient $C_{d}$, and $\bar{H}$ is the mean CAP depth. The bottom stress is neglected since we assume the lower layer is at rest in this simplified framework. The Coriolis force is neglected because, (1) the Rossby number for the flow is considerably greater than unity ( $U=15 \mathrm{~m} \mathrm{~s}^{-1}, f=10^{-4} \mathrm{~s}^{-1}, L=20 \mathrm{~km}$ ), and (2) the terrain geometry of the Valley produces channeled flows (c.f., Fig. 11), which limits the degree of Coriolis turning.

The CAP slope, $\partial H / \partial x$, in Eq. 4 is balanced by both the pressure gradient aloft (first term on the right-hand side) and the shear stress divergence acting on the CAP (second term on the right-hand side). When the balance is dominated by the pressure gradient term it is referred to as the static adjustment, or inverse barometer response, reflecting the change in depth of the cold (dense) air required to exactly offset the pressure gradient aloft (Gill 1982; Petkovšek and Vrhovec 1994; Zängl 2003). Similarly, the balance between the shear stress divergence and the CAP slope is referred to as the dynamic response, physically representing 
the "piling up" of cold air at the downwind end of the basin (Gubser and Richner 2001). For lakes and oceans this effect is known as storm surge or wind set-up (Gill 1982).

Zängl (2003) demonstrates that the static adjustment for a linearly stratified CAP may be approximated using Margule's formula and the hydrostatic equation. The CAP slope required to offset the synoptic-scale pressure gradient is then given by

$$
H(x)=\sqrt{\frac{2 R T^{2}}{P g}} \sqrt{\frac{\partial P / \partial x}{\left(\gamma_{1}-\gamma_{2}\right)} x},
$$

where $H(x)$ is the height of the CAP top that is primarily a function of the pressure gradient $(\partial P / \partial x)$ immediately above the CAP, the difference in lapse rates $\left(\gamma_{1}-\gamma_{2}\right)$, where $\gamma_{1}$ and $\gamma_{2}$ refer to the CAP and ambient lapse rates, respectively, and the distance $x$ from the edge of the cold air as well as the temperature $T$ and pressure $P$ immediately above the CAP. Using Eq. 5 and values from Fig. $15\left(\partial P / \partial x=-1.25 \times 10^{-3} \mathrm{~Pa} \mathrm{~m}^{-1}, T=282.5 \mathrm{k}, P=\right.$ $\left.816.5 \times 10^{2} \mathrm{~Pa}, \gamma_{1}=-0.0098 \mathrm{~km}^{-1}, \gamma_{2}=0.022 \mathrm{~km}^{-1}\right)$ the required change in elevation of the CAP top to balance the synoptic-scale pressure gradient aloft is $225 \mathrm{~m}$ over $22 \mathrm{~km}$, which is roughly half the observed elevation change estimated earlier.

Hence, the dynamic forcing must be roughly the same magnitude as the static forcing in order to maintain the observed steeper slope of the CAP. For such a steady-state situation to exist, the up-pressure gradient winds transporting mass downstream within the CAP have to be balanced antitriptically through downward momentum flux into the CAP from the flow aloft. Similar antitriptic balances are reported in other boundary-layer flows (Sun et al. 2013). Zängl (2003) also simulated steeper slopes than expected from static forcing alone as a result of terrain-channeled ageostrophic flow above a CAP during the approach of a shortwave trough, a scenario similar to our observed case.

The time variation of the CAP tilt is examined using the elevation corrected time series of surface pressure for ISS-S and ISFS-2 (Fig. 11d); ISFS-2 is located near KSLC and at a comparable elevation $(1,289 \mathrm{~m})$. When the corrected pressure at ISFS-2 is higher than that ISS-S the CAP tilt must exceed that required for the static balance. These over tilted periods, centred at 0000, 0300, 0600 and 1100 UTC, correspond to the periods of northward CAP displacement shown in Figs. 3, 4, 5 and 6. In contrast when the cold air advances southward (0100, 0400, 0900, 1400 UTC) the pressure gradient along the valley becomes nearly zero, implying a diminished CAP slope just sufficient to offset the pressure gradient aloft. Following the trough passage at 1500 UTC the synoptic-scale pressure gradient weakens and the CAP returns to a horizontally homogenous state.

We conclude, then, that the observed CAP geometry during the disturbance phase reflects a three-way balance between the CAP tilt, the pressure gradient aloft, and the wind-stress divergence. This balance can, however, be easily disrupted by changes in the wind speed or pressure gradient aloft. For example, a sudden decrease in the wind stress at the CAP top would leave the CAP tilt unbalanced, prompting a "collapse" of the CAP slope and a displacement of the CAP edge. This may help explain the advance and retreat of the CAP described in the above sections as well as the gravity current characteristics of the advancing cold air as it passed over ISS-S.

\subsection{Kelvin-Helmholtz Instability}

Many high frequency (order of minutes) waves are observed during the disturbance phase of IOP-1 (cf. Fig. 9). Amongst these waves we are particularly interested in those resulting from Kelvin-Helmholtz instability, which occurs in stratified shear flow when the kinetic energy 

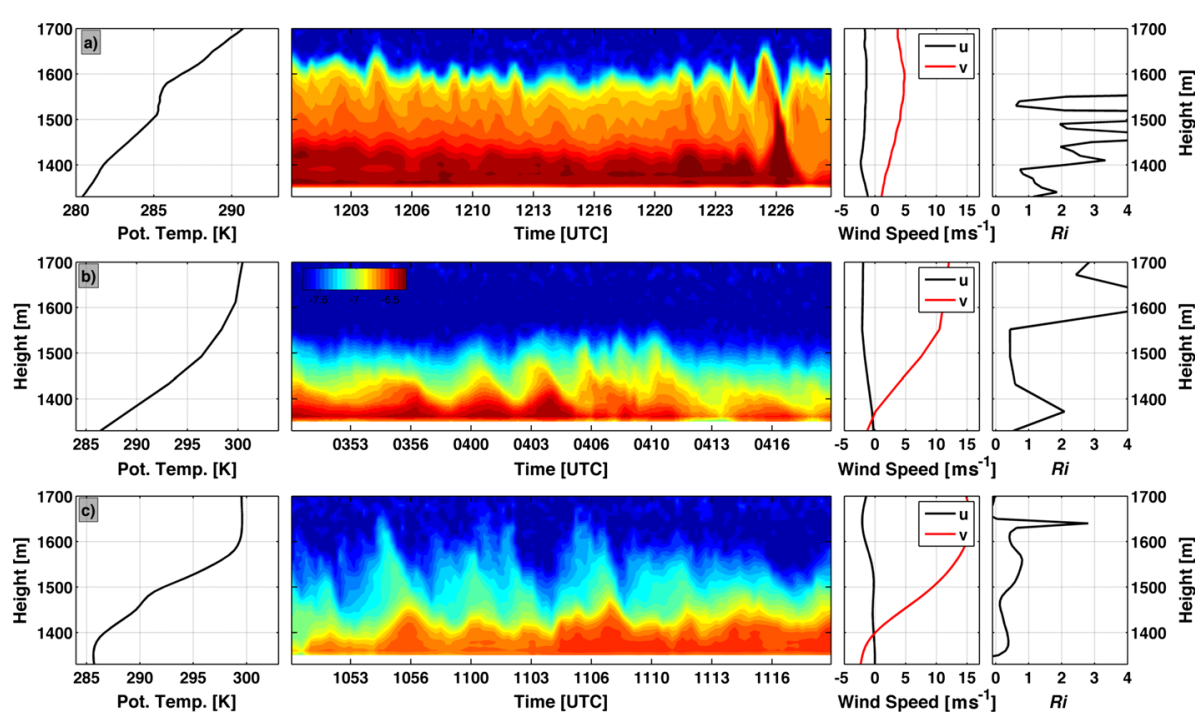

Fig. 12 Kelvin-Helmholtz waves at: a 1200 UTC 2 December, b 0400 UTC 3 December, and c 1100 UTC 3 December. First column potential temperature. Second column aerosol backscatter. Third column wind speed. Last column gradient Richardson number. All data are from ISS-S excepting the profile data in the first row, which is from KSLC

available from shear exceeds the work required to move a parcel against the stratification. The necessary condition for Kelvin-Helmholtz instability is given by the critical gradient Richardson number

$$
R i_{c}=\frac{N^{2}}{\left(\left(\frac{\partial u}{\partial z}\right)^{2}+\left(\frac{\partial v}{\partial z}\right)^{2}\right)} \leq 0.25,
$$

where $N$ is the Brunt-Väisälä frequency, and the terms in the denominator are the components of the vertical wind shear. When $R i$ is subcritical Kelvin-Helmholtz waves may develop, evolving from small perturbations into breaking waves (Nappo 2002). These breaking waves are an important mixing mechanism in stratified geophysical flows, including the stable boundary layer (Fernando 1991; Newsom and Banta 2003; Pinto et al. 2006; Flamant et al. 2006).

During IOP-1, Kelvin-Helmholtz waves are first observed during the onset of the accelerating southerly flow aloft. For example, Fig. 12a shows a sequence of high frequency (1 cycle per min) waves culminating in a billow that inverts the aerosol gradient within the wave crest at 1226 UTC 2 December. A contemporaneous sounding at KSLC indicates the waves are centred within a weakly stable layer between the surface-based and capping inversion layers. The wind shear across this layer is modest, but the Richardson number is nonetheless near critical due to the weak static stability.

High amplitude waves subsequently become a dominant feature of the aerosol backscatter profiles as the flow aloft increases to $10 \mathrm{~m} \mathrm{~s}^{-1}$. Figure $12 \mathrm{~b}$ shows a sequence of these waves at 0400 UTC 3 December wherein 100-m amplitude variations in aerosol depth occur about once every $3 \mathrm{~min}$. The first three waves successively amplify, and the fourth and fifth waves appear to break down into turbulence or smaller scale waves. The Richardson number, here evaluated from our time-height dataset, is near critical over a deep layer. However, since the 

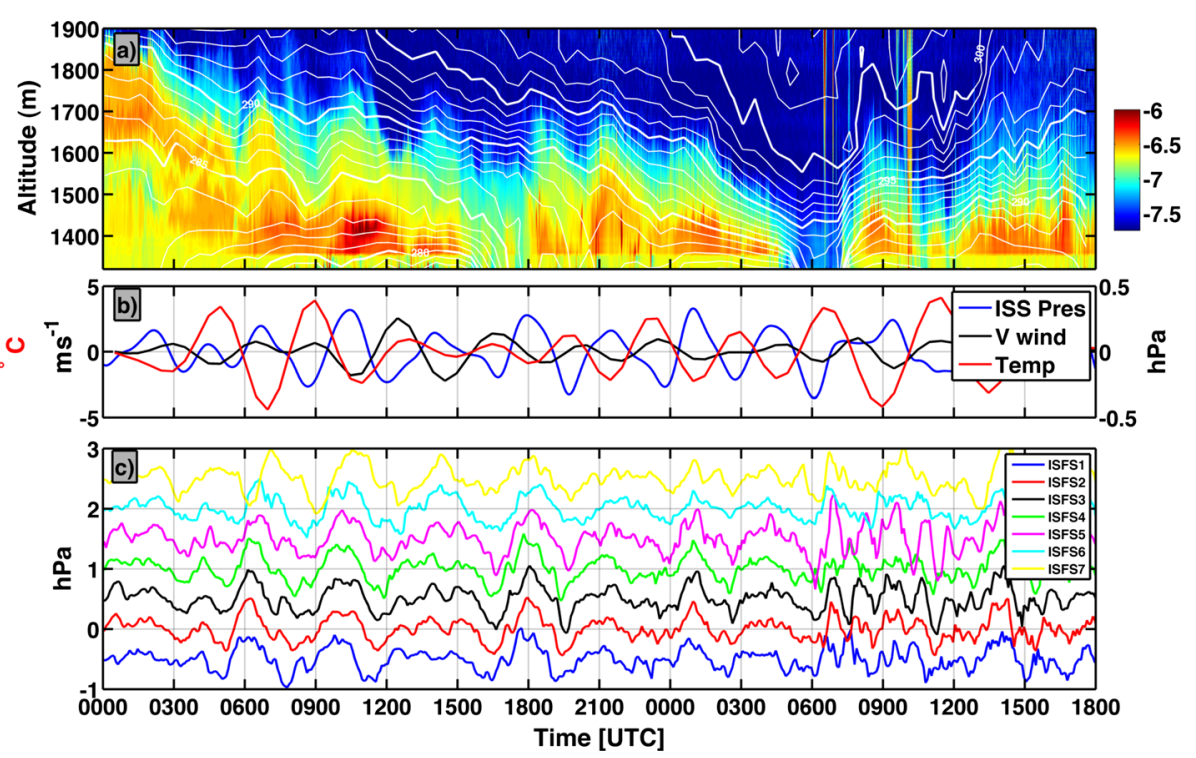

Fig. 13 Conditions at ISS-S from 0000 UTC 2 December to 18003 December of: a aerosol backscatter (shaded) with potential temperature (contours), b Band-pass filtered perturbations of ISS-S surface pressure (blue), and 1,500-1,800 m mean meridional wind (black), and potential temperature (red). c High-pass filtered surface pressure perturbations at each ISFS site. Curves are offset by $0.5 \mathrm{hPa}$

time-height temperature and wind data lack the vertical and temporal resolution to resolve fine scale gradients, it is likely that the minimum values of $R i$ are lower than those calculated.

Later, at 1100 UTC 3 December (Fig. 12c), the winds aloft reach their peak speed of $15 \mathrm{~m} \mathrm{~s}^{-1}$ and strong shear extends over the depth of the CAP. In fact, the shear is now enhanced by northerly flow near the surface. Correspondingly, $R i$ is near its critical value over most of the CAP depth. The waves at this time have amplitudes upwards of $200 \mathrm{~m}$, and appear to loft aerosols deep into the clear air aloft. Compared to earlier, the wave structures are more chaotic and less clearly billow shaped. The wave period remains approximately 3 $\min$.

It is notable that the CAP stratification is not substantively reduced despite the strong wind shear and Kelvin-Helmholtz waves throughout the disturbance phase. For example, downward turbulent heat fluxes of $120 \mathrm{~W} \mathrm{~m}^{-2}$ are observed $50 \mathrm{~m}$ above the surface during the northern most CAP displacement (not shown). This turbulent heating is likely offset by vertical differential temperature advection, with cold-air advection near the surface originating from the deeper portions of the CAP and warm-air advection aloft associated with the approaching trough.

\subsection{Basin-Scale Internal Waves}

Low frequency (order of hours), long wavelength (basin-scale) oscillations are observed in the CAP throughout the disturbance phase of IOP-1 (Fig. 13a). We hypothesize that these waves belong to a group of wave phenomena known as basin-scale internal waves, which include baroclinic seiches and are known to occur within stratified lakes (Csanady 1972; Monismith 1985), but have not been thoroughly documented in atmospheric CAPs (Largeron et al. 2013). 
Basin-scale waves are manifest during IOP-1 as oscillations in the CAP depth superimposed on the broader trends associated with the passage of the shortwave trough (Fig. 13a). Visual inspection of the potential temperature and aerosol backscatter time-height dataset indicates that the waves have a period of $3 \mathrm{~h}$, arrive with a steep increase in CAP depth, and depart with a more gradual thinning. We attempt to isolate the properties of these waves by applying a $1-5 \mathrm{~h}$ band-pass filter to independent time series of surface pressure (1-min resolution) and the 1,500-1,800 m layer-averaged meridional wind speed and potential temperature at ISS-S (Fig. 13b). The filter removes low frequency variations associated with synoptic-scale and diurnal fluctuations, high frequency variations due to microscale processes (e.g. Kelvin-Helmholtz waves), and preserves the frequencies associated with the waves of interest.

These filtered data show that increases in aerosol-layer depth correspond to increases in surface pressure and decreases in layer-mean temperature (Fig. 13b, i.e., a deeper CAP with higher aerosol concentration is accompanied by higher pressure and lower temperature). Also, the meridional wind component generally reverses sign during the wave cycle, oscillating between more northerly and southerly flow.

These oscillations are coherent over the scale of the Valley, appearing with comparable amplitude $(1 \mathrm{hPa})$ at each of the seven ISFS sites (Fig. 13c). There is an approximate $1 \mathrm{~h}$ time lag between ISFS1 and ISFS7, which are at the northern and southern ends of the valley, respectively, and separated by $31.4 \mathrm{~km}$ (see Fig. 1). Spectral analysis of these time series confirms that the dominant wave period is between 3 and $4 \mathrm{~h}$ (not shown).

The link between surface pressure and CAP depth is further examined for one of these waves as it passes over the Harker's ridge temperature transect between 0515 and 0845 UTC 2 December (Fig. 14a). From these temperature profiles it is apparent that the wave consists of a rise and fall in the depth of the surface-based layer of cold air relative to a mean state. The maximum amplitude in temperature variations occurs between 1,500 and 1,800 m, which coincides with the transition layer separating the surface-based nocturnal inversion from the capping layer aloft. This transition layer is apparent in the individual profiles as a nearly adiabatic lapse rate centred at about 1,600 $\mathrm{m}$.

Following Li et al. (2009), the hydrostatic pressure perturbation at the surface can be approximated from these temperature anomalies during the CAP oscillation using

$$
P^{\prime}(z=0) \approx \frac{\bar{\rho} g}{\bar{T}} \int_{z=0}^{z=H} T^{\prime}(z) d z
$$

where $\bar{T}$ is the mean temperature, $T^{\prime}(z)$ is the perturbation temperature at each height, $\bar{\rho}$ is the mean density, and $H$ is the depth of the CAP. The pressure perturbation is thus the departure of the surface pressure from the time mean pressure during the period of analysis, which in this case is $3 \mathrm{~h}$. The computed pressure anomalies (Fig. 14b) confirm that as the CAP rises (falls) the surface pressure increases (decreases) by about $0.4 \mathrm{hPa}$, giving a total wave amplitude of $0.8 \mathrm{hPa}$, consistent with the pressure perturbations measured throughout the valley (Fig. 13c). The temporal variations of computed pressure anomalies are also consistent with the sharp initial rise followed by gradual reduction in pressure observed at each of the ISFS sites (Fig. 13c) and apparent in the aerosol backscatter (Fig. 13a).

The exact causal mechanism and dynamics of these basin-scale internal waves are as, yet unknown. They may arise due to any of a number of forcings acting upon the CAP. For example, it is possible that they are a response to an external forcing, such as the increasing winds aloft, or an internal forcing, such as katabatic flows and lake breezes that are known to occur within the Valley during CAPs. Regardless of their source, these oscillations are an 
Fig. 14 a Harker's Ridge temperature profiles every $5 \mathrm{~min}$ between 0525 and 0830 UTC during the passage of one BSIW. Red lines indicate the mean and extreme profiles and the dashed green lines are adiabats. b The surface pressure perturbation computed from temperature anomalies
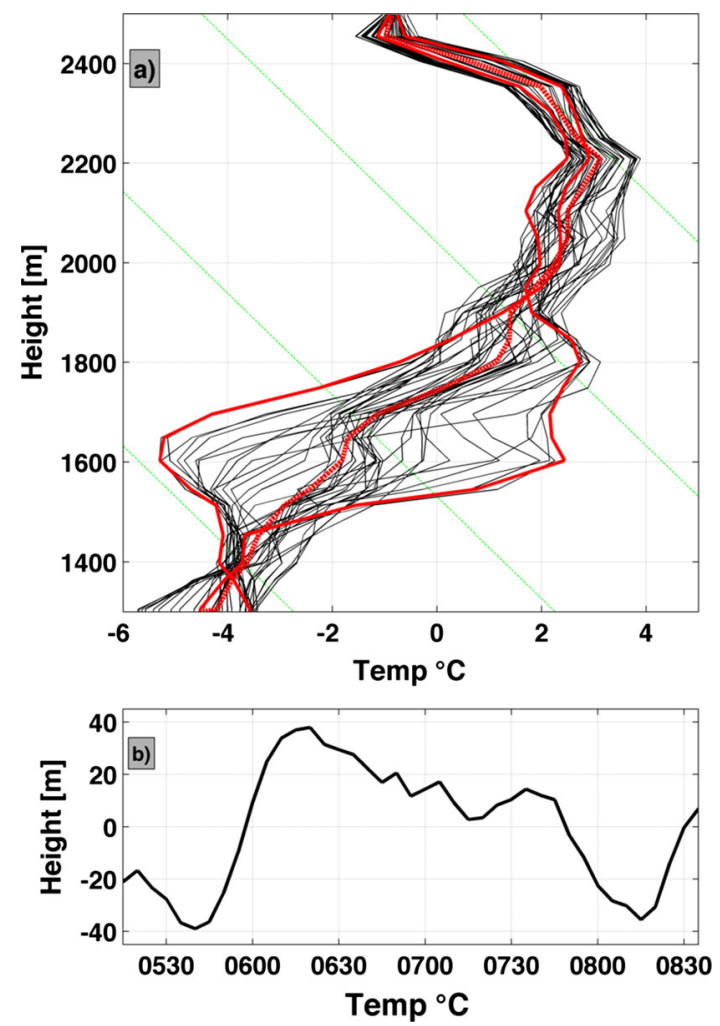

important factor in local changes in the CAP. For example, it is possible that these waves disrupt the three-way force balance described in Sect 3.5 and contribute to the advance and retreat of the cold air.

\section{Summary and Conclusions}

In this paper we have documented the complex evolution of a persistent cold-air pool (CAP) that was disturbed by a passing shortwave trough. We show that the initially horizontally homogenous stratified air mass was disrupted by a series of along-valley displacements, frontal passages, internal waves, and turbulent mixing. To synthesize these elements of the trough-CAP interaction we present here a schematic of the CAP evolution (Fig. 15) using insights from the observational data and the numerical simulation.

The stages of the CAP disruption are as follows:

(a) At the onset, a quiescent and horizontally homogenous two-layered CAP resides in the valley. Synoptic-scale warming aloft modulates the upper stable layer, while the surfacebased inversion is affected by diurnally varying sensible heat fluxes. The layers are partially separated by a residual layer of weaker stability (Fig. 15a).

(b) Winds above the CAP increase as a disturbance approaches. A mountain wave develops in the stratified cross-barrier flow over the upstream topography, generating downslope warming and accelerated flow. The plunging flow displaces and erodes the surface inver- 

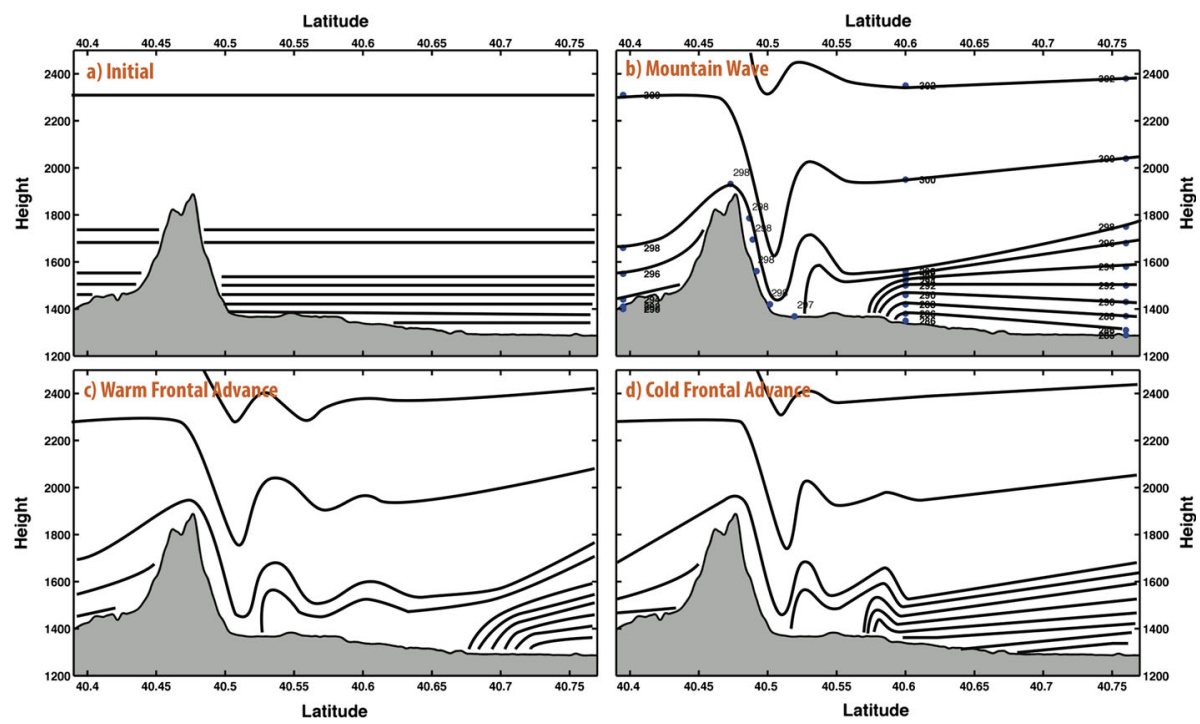

Fig. 15 Schematic of CAP displacement. a Initially horizontally homogenous CAP. b Onset of a mountain wave and CAP displacement. c Advancing warm front due to the retreat of the tilted CAP. d Cold frontal advance due to the collapse of the CAP tilt. Selected potential temperature observations from soundings and surface stations are shown in $\mathbf{b}$

sion, forming a frontal interface. Increased shear leads to Kelvin-Helmholtz waves, especially at the top of the surface-inversion layer (Fig. 15b).

(c) The CAP tilts upward in the downwind direction, establishing a force balance between the internal hydrostatic pressure gradient, the external pressure gradient, and the windstress divergence acting on the CAP. As the CAP tilts, its southern edge advances through the valley as a warm front, providing warmer, windier, and cleaner air to southern locales (Fig. 15c).

(d) A perturbation, such as a temporary reduction in wind stress or a wave-modulated change in CAP depth, disrupts the CAP force balance. The CAP tilt partially collapses due to the unbalanced internal pressure gradient, sending a shallow density current propagating upwind through the valley and restoring the surface-based inversion. Enhanced KelvinHelmholtz wave mixing occurs in the wake of the density current (Fig. 15d).

Stages b-d repeat as the three-way force balance is restored leading to a sequence of frontal advances and retreats over upwind portions of the valley. Meanwhile northern locales remain within the CAP throughout the evolution. Finally, the winds aloft diminish and the CAP tilt collapses for a final time, restoring horizontally homogenous and quiescent CAP conditions throughout the valley.

While this simple schematic summary relies primarily on data from IOP-1, it nonetheless fits well with observations from many other CAPs, which are common in the Valley. For example, a similar sequence of step-like frontal temperature changes was observed at ISS-S during PCAPS IOP-4 (not shown). Moreover, many of the details of the IOP-1 CAP are similar to the evolution of the CAPs described by Whiteman et al. (2001) and Flamant et al. (2006). Namely, a CAP is displaced in strong pre-frontal downslope winds leading to a warm front that provides partial or complete valley ventilation. In the present case, the CAP displacement is reversible, and CAP conditions are restored after winds abate. In other instances, however, a CAP may be completely removed, suggesting that irreversible turbulent mixing and spillover at the downwind end of the basin play an important role in CAP destruction. 
We conclude by noting that many of the key features in the trough-CAP interaction are mesoscale and microscale processes that are typically either poorly resolved or altogether unresolved in numerical forecast guidance. These unresolved processes strongly affect the CAP, and thus the forecasts for air quality. To further address the sensitivity of CAP removal to mountain waves, hydraulic jumps, Kelvin-Helmholtz waves, and basin-scale internal waves a companion study using a larger set of idealized large-eddy simulations than the single simulation used to generate Fig. 8 is planned.

Acknowledgments We thank three anonymous reviewers for their useful comments in improving this manuscript. We greatly appreciate the individuals and entities involved in PCAPS: staff from agencies (NCAR Earth Observing Laboratory ISS and ISFS Groups, Utah Division of Air Quality, Utah Department of Transportation, National Weather Service Forecast Office, Dugway Proving Ground, and Kennecott Utah Copper); faculty, staff and students at academic institutions (University of Utah, San Jose State University and San Francisco State University), and other volunteers. Of particular note are the individuals in the Mountain Meteorology Group at the University of Utah: C. David Whiteman for his leadership of the project and feedback related to this research; Sebastian Hoch for his installation of the HOBO sensors and other data collection efforts; Joseph Young for his processing of the ceilometer data; and Erik Crosman for his feedback on this research. The support and resources from the Center for High Performance Computing at the University of Utah are gratefully acknowledged. This research is supported by Grant ATM-0938397 from the National Science Foundation.

Open Access This article is distributed under the terms of the Creative Commons Attribution License which permits any use, distribution, and reproduction in any medium, provided the original author(s) and the source are credited.

\section{References}

Barnes SL (1964) A technique for maximizing details in numerical weather map analysis. J Appl Meteorol 3:396-409

Beard JD, Beck C, Graham R, Packham S, Traphagan M, Giles R, Morgan JG (2012) Winter temperature inversions and emergency department visits for Asthma in Salt Lake County, Utah, 2003-2008. Environ Health Perspect 120:1385-1390

Bell RC, Thompson R (1980) Valley ventilation by cross winds. J Fluid Mech 96:757-767

Chen Y, Ludwig FL, Street RL (2004) Stably stratified flows near a notched Transverse Ridge across the Salt Lake Valley. J Appl Meteorol 43:1308-1328

Csanady GT (1972) Response of large stratified lakes to wind. J Phys Oceanogr 2:3-13

Durran DR (1986) Another look at downslope windstorms. Part I: The development of analogs to supercritical flow in an infinitely deep, continuously stratified fluid. J Atmos Sci 43:2527-2543

Flamant C, Drobinski P, Furger M, Chimani B, Tschannett S, Steinacker R, Protat A, Richner H, Gubser S, Haberli C (2006) Föhn/CAP interactions in the Rhine valley during MAP IOP 15. Q J R Meteorol Soc 132:3035-3058

Fernando HJS (1991) Turbulent mixing in stratified fluids. Annu Rev Fluid Mech 23:455-493

Gill A (1982) Atmosphere-ocean dynamics. Academic Press, New York, 662 pp

Gillies RR, Wang SY, Booth MR (2010) Atmospheric scale interaction on wintertime Intermountain West low-level inversions. Weather Forecast 25:1196-1210

Gubser S, Richner H (2001) Investigations into mechanisms leading to the removal of the cold-pool in foehn situations. Extended abstracts from MAP meeting at Schliersee. MAP Newsletter 15. Available at: http:// www.map.meteoswiss.ch/map-doc/NL15/gubser2.pdf

Horel J, Splitt M, Dunn L, Pechmann J, White B, Ciliberti C, Lazarus S, Slemmer J, Zaff D (2002) Mesowest: cooperative mesonets in the western United States. Bull Am Meteorol Soc 83:211-225

Jiang Q, Doyle JD, Wang S, Smith RB (2007) On boundary layer separation in the lee of mesoscale topography. J Atmos Sci 64:401-420

Largeron Y, Staquet C, Chemel C (2013) Characterization of oscillatory motions in the stable atmosphere of a deep valley. Boundary-Layer Meteorol 148:439-454

Lareau NP, Crosman E, Whiteman CD, Horel JD, Hoch SW, Brown WOJ, Horst TW (2013) The persistent cold-air pool study. Bull Am Meteorol Soc 94:51-63 
Lee TJ, Pielke RA (1989) Influence of cold pools downstream of mountain barriers on downslope winds and flushing. Mon Weather Rev 117:2041-2058

Lee JT, Lawson RE Jr, Marsh GL (1987) Flow visualization experiments on stably stratified flow over ridges and valleys. Meteorol Atmos Phys 37:183-194

Li Y, Smith RB, Grubišić V (2009) Using surface pressure variations to categorize diurnal valley circulations: experiments in Owens Valley. Mon Weather Rev 137:1753-1769

Malek E, Davis T, Martin RS, Silva PJ (2006) Meteorological and environmental aspects of one of the worst national air pollution episodes in Logan, Cache Valley, Utah, USA. Atmos Res 79:108-122

Monismith SG (1985) Wind forced motions in stratified lakes and their effects on mixed-layer shear. Limnol Oceanogr 30:771-783

Nappo CJ (2002) An introduction to atmospheric gravity waves. Academic Press, New York, 279 pp

Newsom RK, Banta RM (2003) Shear-flow instability in the stable nocturnal boundary layer as observed by Doppler Lidar during CASES-99. J Atmos Sci 60:16-33

Pataki DE, Tyler BJ, Peterson RE, Nair AP, Steenburgh WJ, Pardyjak ER (2005) Can carbon dioxide be used as a tracer of urban atmospheric transport? J Geophys Res 110:D15102

Pataki DE, Bowling DR, Ehleringer JR, Zobitz JM (2006) High resolution atmospheric monitoring of urban carbon dioxide sources. Geophys Res Lett 33:L03813

Petkovšek Z (1992) Turbulent dissipation of cold air lake in a basin. Meteorol Atmos Phys 47:237-245

Petkovšek Z, Vrhovec T (1994) Note on the influences of inclined fog lakes on the air pollution in them and on the irradiance above them. Meteorol Z 3:227-232

Pinto JO, Parsons DB, Brown WOJ, Cohn S, Chamberlain N, Morley B (2006) Coevolution of down-valley flow and the nocturnal boundary layer in complex terrain. J Appl Meteorol 45:1429-1449

Pope CA III, Ezzati M, Dockery DW (2009) Fine-particulate air pollution and life expectancy in the United States. N Engl J Med 360:376-386

Rakovec J, Merše J, Jernej S, Paradiž B (2002) Turbulent dissipation of the cold-air pool in a basin: comparison of observed and simulated development. Meteorol Atmos Phys 79:195-213

Reddy PJ, Barbarick DE, Osterburg RD (1995) Development of a statistical model for forecasting episodes of visibility degradation in the Denver metropolitan area. J Appl Meteorol 34:616-625

Reeves HD, Stensrud DJ (2009) Synoptic-scale flow and valley cold pool evolution in the western United States. Weather Forecast 24:1625-1643

Schönlieb C-B (2012) Applying modern PDE techniques to digital image restoration. Mathworks Newsletter. Available at: http://www.mathworks.com/company/newsletters/articles/applyingmodern-pde-techniques-to-digital-image-restoration.html

Silcox GD, Kelly KE, Crosman ET, Whiteman CD, Allen B (2012) Wintertime PM2.5 concentrations in Utah's Salt Lake Valley during persistent, multi-day cold-air pools. Atmos Environ 46:17-24

Simpson JE (1997) Gravity currents in the environment and the laboratory. Cambridge University Press, Cambridge, 244 pp

Skamarock WC, Klemp JB, Dudhia J, Gill DO, Barker DM, Duda MG, Huang X, Want W, Power JG (2008) A description of the advanced research WRF version 3. NCAR Technical Note. NCAR/TN-475+STR, $113 \mathrm{pp}$

Strang EJ, Fernando HJS (2001a) Entrainment and mixing in stratified shear flows. J Fluid Mech 428:349-386

Strang EJ, Fernando HJS (2001b) Vertical mixing and transports through a stratified shear layer. J Phys Oceanogr 31:2026-2048

Sun J, Lenschow DH, Marht L, Nappo C (2013) The relationships among wind, horizontal pressure gradient, and turbulent momentum transport during CASES-99. J Atmos Sci 70:3397-3414

Tampieri F, Hunt JCR (1985) Two-dimensional stratified fluid flow over valleys: linear theory and laboratory investigation. Boundary-Layer Meteorol 32:257-279

Tyndall DP, Horel JD (2013) Impacts of mesonet observations on meteorological surface analyses. Weather Forecast 28:254-269

U.S. EPA (cited 2013) National Ambient Air Quality Standards (NAAQS). Available online at http://www. epa.gov/air/criteria.html

Vosper SB (2004) Inversion effects on mountain lee waves. Q J R Meteorol Soc 130:1723-1748

Wei L, Pu Z, Wang S (2013) Numerical simulation of the life cycle of a persistent wintertime inversion over Salt Lake City. Boundary-Layer Meteorol 148:399-418

White BL, Helfrich KR (2012) A general description of a gravity current front propagating in a two-layer stratified fluid. J Fluid Mech 711:545-575

Whiteman CD, Bian X, Zhong S (1999) Wintertime evolution of the temperature inversion in the Colorado Plateau Basin. J Appl Meteorol 38:1103-1117

Whiteman CD, Zhong S, Shaw WJ, Hubbe JM, Bian X, Mittelstadt J (2001) Cold pools in the Columbia basin. Weather Forecast 16:432-447 
Wolyn PG, McKee TB (1989) Deep stable layers in the intermountain western United States. Mon Weather Rev 117:461-472

Young J (2013) Investigation of wintertime cold-air pools and aerosol layers in the Salt Lake Valley using a laser ceilometer. MS Thesis, University of Utah, $118 \mathrm{pp}$

Zängl G (2003) The impact of upstream blocking, drainage flow and the geostrophic pressure gradient on the persistence of cold-air pools. Q J R Meteorol Soc 129:117-137

Zängl G (2005) Winterime cold-air pools in the Bavarian Danube Valley Basin: data analysis and idealized numerical simulations. J Appl Meteorol 44:1950-1971

Zardi D, Whiteman CD (2013) Diurnal mountain wind systems. In: Chow K, De Wekker SFJ, Synder B (eds) Mountain weather research and forecasting: recent progress and current challenges. Springer, New York, pp 35-119

Zhong S, Whiteman CD, Bian X, Shaw WJ, Hubbe JM (2001) Meteorological processes affecting evolution of a wintertime cold air pool in a large basin. Mon Weather Rev 129:2600-2613

Zhong S, Bian X, Whiteman CD (2003) Time scale for cold-air pool breakup by turbulent erosion. Meteorol Z 12:229-233 